\title{
DNA end-resection in highly accessible chromatin produces a toxic break
}

Jeroen van den Berg ${ }^{1,2}$, Stacey E.P. Joosten ${ }^{1,3}$, YongSoo Kim ${ }^{1,3}$, Anna G. Manjón ${ }^{1,2}$ Lenno Krenning ${ }^{1,2}$, Lisa Koob ${ }^{1,2}$, Femke M. Feringa ${ }^{1,2}$, Rob Klompmaker ${ }^{1,2}$, Bram van den Broek², Kees Jalink², Wilbert Zwart ${ }^{1,3,4}$ \& René H. Medema $a^{1,2,5}$

${ }^{1}$ Oncode Institute, ${ }^{2}$ Division of Cell Biology, ${ }^{3}$ Division of Oncogenomics, The Netherlands Cancer Institute, Plesmanlaan 121, 1066 CX, Amsterdam, The Netherlands. ${ }^{4}$ Laboratory of Chemical Biology and Institute for Complex Molecular systems, Department of Biomedical Engineering Eindhoven University of Technology, Eindhoven, The Netherlands ${ }^{5}$ correspondence to: r.medema@nki.nl

Abstract

Of all damage occurring to DNA, the double strand break (DSB) is the most toxic lesion. Luckily, cells have developed multiple repair pathways to cope with these lesions. These different pathways compete for the same break, and the location of the break can influence this competition. However, the exact contribution of break location in repair pathway preference is not fully understood. We observe that most breaks prefer classical non-homologous end-joining, whereas some depend on DNA end-resection for their repair. Surprisingly, we find that for a subset of these sites, the activation of resection-dependent repair induces a detrimental DNA damage response. These sites exhibit extensive DNA end-resection due to improper recruitment of 53BP1 and the Shieldin complex due to low levels of H4K20me. Most of these sites reside in close proximity to DNAsel hypersensitive sites. Compacting or removing these regions reduces extensive DNA end-resection and restores normal repair. Taken together, we found that DSB in open chromatin is highly toxic, due to the improper activity of 53BP1 and Shieldin, resulting in extensive DNA end-resection. 


\section{Introduction}

The human genome is subjected to damage caused by irradiation and a wide variety of chemicals ${ }^{1}$. Besides these exogenous agents, essential cellular processes such as DNA replication \& transcription can compromise genome integrity ${ }^{2,3}$. The most toxic lesion to the DNA threatening this integrity is a DNA doublestrand break (DSB) ${ }^{4}$. Every proliferating cell in our body experiences an estimated 10 to 50 DSBs per day ${ }^{4,5}$. These lesions pose a serious threat to tissue homeostasis, differentiation, and development ${ }^{6-8}$. Moreover, the ability to cope with DNA lesions is required to limit cellular transformation and tumorigenesis ${ }^{3,9}$. Fortunately, multiple pathways are in place to repair DSBs ${ }^{10}$.

DNA repair pathways are naturally competing to resolve DSBs in the gehome. The two canonical pathways for DSB repair are classical non-homologous end-joining (c-NHEJ) and homologous recombination $(\mathrm{HR})^{11}$. The latter is only active in S/G2-phase of the cell cycle and critically depends on high CDK activity that is only present during these stages ${ }^{12}$. HR allows for repair in an error-free manner since it uses the homologous sister chromatid as a template ${ }^{13}$. In contrast, c-NHEJ is error-prone but is active throughout the cell cycle and depends on ligation of processed broken DNA ends, a process that often produces small insertions and deletions ${ }^{14,15}$. C-NHEJ is repressed by resection, which in turn is promoted by BRCA1 and associated proteins at the lesion ${ }^{16}$. Conversely, recruitment of the Shieldin complex, 53BP1, RIF1, and MAD2L2/REV7 inhibits resection at the break site ${ }^{17-21}$, favoring c-NHEJ. In this manner, HR and c-NHEJ compete for the repair of the same breaks in the S and G2 phases of the cell cycle. In addition, back-up pathways such as alternative end-joining and single-strand annealing are in place to deal with DSBs that cannot be repaired by means of HR or c-NHEJ ${ }^{22-24}$. These pathways also rely on DNA endresection and are often dependent on the presence of DNA microhomologies to anneal the broken ends ${ }^{23}$.

Several chromatin remodelers and modifiers that affect the relative activity of the various DNA repair pathways have been identified, which demonstrated that the correct chromatin conformation in proximity to a DSB is critical to ensure successful DNA repair ${ }^{25}$. These findings have sparked an interest in the role of native chromatin on DNA repair pathway choice ${ }^{26-28}$. However, studying the effects of chromatin context on repair pathway choice is not straightforward when using common agents to induce DSBs, such as $\gamma$-irradiation or DNA damaging chemotherapeutics ${ }^{29}$. The random nature of break induction with these 
modalities does not allow for easy quantification of relative pathway usage on a single locus. However, the implementation of CRISPR/Cas9 systems in human cells has allowed the identification of several locationspecific phenotypes in DNA damage responses ${ }^{30-32}$.

Here, we use a Type II CRISPR/Cas9 system to induce locus-specific DSBs ${ }^{33}$. We have previously optimized this system to induce DSBs with high temporal control ${ }^{31}$. We use this system to distinguish location-specific DNA repair pathway activities by visualizing the recruitment of selected DNA repair factors. In addition, we investigate the requirement for specific DNA repair pathways at a given location by inhibition of c-NHEJ (DNA-PKi) or DNA end-resection (Mre11i). We observe that c-NHEJ is the pathway of choice for most of the breaks studied here, whereas a smaller subset engages in resection-dependent repair. Interestingly, we find that activation of DNA end-resection at some of these breaks produces a more detrimental DNA damage response.

We show that these latter detrimental breaks do not properly recruit 53BP1, and as a consequence, resection is not inhibited. Extensive resection at these sites can be rescued by ectopic recruitment of the Shieldin complex, a downstream effector of 53BP1, that actively inhibits end-resection ${ }^{20}$. We find that detrimental breaks correlate to DNAsel hypersensitive sites, implying that these breaks occur in open chromatin. Indeed, removal of nascent open chromatin reduces DNA damage responses following break induction. Increasing the efficacy of radiotherapy with a (chemo-)adjuvant is often referred to as radiosensitization. Most radio-sensitizers rely on blocking DNA damage checkpoints or DNA repair pathways ${ }^{34-}$ ${ }^{36}$. However, inhibitors of histone deacetylases (HDAC) have been characterized as radio-sensitizer lacking a clear link to DNA repair or checkpoints ${ }^{37}$.

Finally, many studies have tried to implicate this mechanism of action to the inhibition of DNA damage checkpoints or DNA repair deficiencies (extensively reviewed in Groselj et al., 2013) ${ }^{38}$. Although most studies have suggested a role for HDAC in promoting DNA repair, no clear targets of HDAC inhibitors were consistently identified with described roles in DNA repair. We show that the opening up of chromatin, with vorinostat, result in activation of DNA end resection. This increased level of DNA end resection results in a detrimental DDR leading to lower survival in these cells. This shows that chromatin relaxation enables increased DNA end resection which is toxic to cells. 


\section{Results}

\section{Genomic location dictates repair pathway preference}

Multiple efforts have been undertaken to determine the contribution of local chromatin and transcriptional status in regulating the choice of the pathway at specific locations in the genome $30,39,40$. However, these attempts were limited to the specificities of site-specific endonucleases (e.g. I-Ppol or AsiSI) or depended on the introduction of novel restriction sites in the genome (I-Scel). Now, we can target specific loci in the genome with CRISPR/Cas9, which allows us to study location-dependent effects on repair in relation to the outcome of the DDR. Using this system, we have previously shown that breaks in the 45S rDNA repeats are more detrimental to cell viability than breaks in the $5 S$ rDNA repeats ${ }^{30}$

To study location-dependent effects outside the rDNA, we designed two guide RNAs (gRNAs) which each target a specific GAPDH pseudogene that is present in multiple copies in the human genome. Most pseudogenes arise from gene duplications or retrotransposition ${ }^{41}$, so targeting pseudogenes with the CRISPR/Cas9 can produce multiple on-target breaks (Fig. 1A) ${ }^{31}$. We designed gRNAs against the GAPDHP46 (P46, 13 loci) and GAPDHP63 (P63, 18 loci) pseudogenes. As expected, eight hours following transfection, these gRNAs induced DSBs as illustrated by the appearance of damage-induced foci of $\gamma \mathrm{H} 2 \mathrm{AX}$ and 53BP1 (Fig. 1B, C). The presence of both Cas9 and gRNA led to an average of 12 or 15 DNA breaks for P46 and P63, respectively (Fig. 1C). No breaks were induced in the absence of Cas9 expression (Fig. 1C). Thus, this system allows us to investigate responses upon DNA damage on multiple locations by the use of a single gRNA ${ }^{31}$.

Since HR and c-NHEJ activities are described to be mutually exclusive ${ }^{17}$, we hypothesized that a single DSB is able to recruit either NHEJ- or HR-associated repair proteins. To obtain a first indication of how frequently these breaks engage in c-NHEJ, we monitored for the presence of activated DNA-PK. Active DNA-PK is phosphorylated on Ser2056 ${ }^{42}$, and phospho-specific antibodies recognizing this site can be used as a surrogate marker for engagement in c-NHEJ43. Activation of DNA-PK, as evidenced by Ser2056 phosphorylation, was more frequently observed at DSBs generated by the P63 gRNA as compared to the P46 gRNA (Fig. 1D, E). This implies that the P63 gRNA target sites have a greater preference for c-NHEJ 
than the P46 gRNA target sites. Next, to obtain a first indication of how frequently these sites engage in resection-dependent repair, we visualized the number of RAD51-positive foci after Cas9-induced breaks. Rad51 is loaded onto the single-stranded DNA that is created through DNA end-resection ${ }^{23,44}$. Interestingly, we observed a higher percentage of RAD51-positive $\gamma \mathrm{H} 2 \mathrm{AX}$ foci in cells containing the $P 46$-induced breaks compared to cells containing P63-induced breaks (Fig.1F, G). This indicates that target sites of the P46 gRNA are present in regions which are more permissive for repair by resection-dependent pathways. Conversely, the resection-dependent repair was limited on the P63-induced break sites, consistent with the earlier observation that these are more prone to engage in c-NHEJ. Taken together, these data imply that repair pathway preference is influenced by the location of the DNA break.

To confirm that $P 46$ - or $P 63$-associated breaks are indeed preferentially repaired by different repair pathways, we used clonogenic assays to determine the sensitivity of both $P 46$ and $P 63$ to inhibition of cNHEJ versus inhibition of DNA end-resection. c-NHEJ can be blocked by inhibition of DNA-PKcs ${ }^{45}$, whereas resection-dependent repair can be-blocked by inhibition of Mre11 (Fig. $1 \mathrm{H})^{46,47}$. We first determined the proper dose for the DNA-PKCS inhibitor (NU-7441) and the Mre11 inhibitor (Mirin) at which these compounds do perturb repair (Fig. 1I, Suppl. Fig. 1E) but do not affect cell viability or cell cycle progression (Suppl. Fig. 1A-D). Next, we used both compounds to study the relative pathway requirements of the P63vs P46-associated breaks. Consistent with the difference pathway preference we observed when staining for pSer2056 DNA-PKcs or RAD51, we observe that cells transfected with the P63 gRNA were more sensitive to NU7441 or DNA-PKcs siRNA, as compared to cells transfected with the P46 gRNA (Fig.1 J, K, Suppl. Fig. 1F, G). Notably, the inverse was observed when cells were treated with an inhibitor or siRNA for Mre11 (Fig.1J, K, Suppl. Fig. 1F, G). In this case, the cells exposed to the P46gRNA were sensitive to inhibitor or siRNA for Mre11, both producing a more prominent inhibition of colony outgrowth after transfection of the P46 gRNA. Strikingly, inhibition of Mre11 in cells transfected with the P63 gRNA led to an increase in colony outgrowth, implying that the engagement by resection-dependent repair of some specific sites targeted by the P63 gRNA can be more detrimental to cell viability. To illustrate that these breaks required different DNA repair pathways to remove DSBs, we allowed cells to repair P46- and P63breaks. First, we observe that the repair of P63-associated breaks occurs at a similar rate as P46associated breaks in the first phase of DNA repair (5 hours following break formation, Suppl. Fig. $1 \mathrm{H}$ ). 
However, we observed that the repair tapers off with P63-associated breaks at later time points, but not with P46-associated breaks. This indicates that a portion of DSBs induced by P63 gRNA are problematic to repair. In order to determine which repair pathways mediate this delayed repair, we treated cells with inhibitors for DNA end-resection and c-NHEJ. We observed that P46-associated breaks depend on DNA end-resection to resolve their DSBs efficiently (Fig. 1L), whereas P63-associated breaks depend on cNHEJ and not on DNA end-resection. In addition, we observe that the inhibition of DNA end-resection (Mre11i) on P63-associated breaks results in increased repair rates. This indicates that a subset of these DNA breaks is converted to problematic repair intermediates once DNA end-resection processes them for DNA repair.

These data indicate that the genomic location of a break influences repair pathway preference, resulting in selective sensitivity towards the loss of different DNA repair pathways. In addition, they reveal that certain sites in the human genome can trigger a toxic DNA damage response when they engage in DNA end-resection. Taken together, using this system we can reveal repair pathway selectivity and relative toxicity of a DNA break across different locations in the genome.

\section{A subset of breaks is deleterious for cell proliferation upon activation of DNA end-resection}

Our data thus far shows that there are qualitative differences between specific double-strand breaks regarding repair pathway selectivity. However, P46- and P63-induced breaks differ in both number and in location, so we cannot discriminate whether pathway selectivity or the number of breaks, determine the extent of inhibition of cell viability. Therefore, we decided to investigate pathway selectivity in the context of a single DSB. To this end, we designed 18 independent gRNAs each uniquely targeting a single site two kilobases adjacent to one of the original P63-sites. We first transfected each individual gRNA and quantified the number of 53BP1 foci (Fig. 2A). We observed that each gRNA induces approximately one DSB above background (Fig. 2A). Furthermore, using targeted indel sequencing (TIDE) we could observe cutting efficiencies between 40 and 70 percent (Suppl. Fig. 2A). In addition, we confirmed that DNA break formation 
induced by the combined set of 18 independent gRNAs (pool) was similar to that seen using P63 (Fig.2B). This indicates that 18 independent gRNAs are efficiently transfected each of these into single cells. Next, we wondered whether the preference to engage DNA repair pathways were similarly skewed towards cNHEJ in the pool compared to P63. Therefore, we stained for either pSer2056 DNA-PKcs (c-NHEJ) or RAD51 (DNA end-resection) and quantified colocalization with $\gamma \mathrm{H} 2 \mathrm{AX}$ (Fig. 2C-E). In both the pool and $P 63$, repair preference is skewed towards C-NHEJ whereas the levels of DNA end-resection are limited on these breaks. To further prove location-dependent DNA repair pathway selectivity, we challenged the pool or P63 with inhibitors or depletions for either DNA-PKcs or Mre11 (Fig. 2F-G). We observe that both conditions display decreased survival in the absence of DNA-PKcs or its inhibition. In contrast, the loss of DNA end-resection increases survival in the presence of both the pool- and P63-associated breaks. This indicates that most of these breaks are dependent on c-NHEJ for their repair. Conversely, the activation of DNA end-resection on these breaks appears to be detrimental to cell viability. These findings imply that the location of a break intrinsically determines selectivity for specific DNA repair pathways.

Historically, it was thought that DNA repair pathway choices were a consequence of the cell cycle stage in which repair takes place. However, recent data have shown that distinct chromatin domains (e.g.

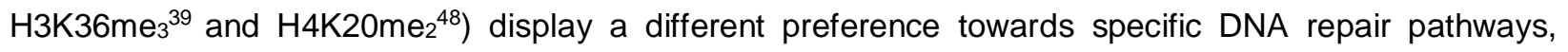
implying that genomic location is an important determinant of pathway preference. In line with this, we observe that breaks generated by the pool of 18 individual P63 gRNAs displays the same repair preferences compared to the original P63 gRNA. Given these observations, we wondered whether repair pathway dependencies vary significantly across the individual sites. To this end, we investigated if the survival of cells challenged with individual breaks was affected by the inhibition of c-NHEJ or DNA end-resection. Therefore, we performed a clonogenic assay to determine the fraction of cells surviving the DNA break induced by each of the individual single-cutting gRNAs (P63.1 to P63.18) (Fig. 2H).

We find that for 15 of the $18 \mathrm{gRNAs}$ survival is decreased when c-NHEJ is inhibited (Fig. 2H, P63.18, P63.10-14, P63.16 and P63.17), which is in line with the fraction of sites that activate DNA-PKcs in the cells transfected with the p63 gRNA pool (Fig. 2E-F). In the case of the other gRNAs (Fig. 2H, P63.9, P63.15 and P63.18), we do not observe a survival defect upon inhibition of c-NHEJ (DNA-PKi). This implies 
that for a large fraction (15/18) of these breaks, the activity c-NHEJ is required for survival after break formation.

Next, we asked how many of these breaks are repaired in a resection-dependent manner. For this, we inhibited Mre11 and determined if this affected survival after break formation. We find that for 10 out of 18 gRNAs (P63.1, P63.3, P63.5, P63.6, P63.8, P63.11-14, and P63.16), Mre11 activity is required for cell survival (Fig. 2H), implying that these breaks are repaired at least in part by resection-dependent repair. In contrast, for 3 of the $18 \mathrm{gRNAs}$ (P63.2, P63.10, and P63.17), we did not observe any detrimental effects of blocking DNA end-resection, implying that these do not depend on the resection-dependent repair. But most strikingly, for the remaining breaks (5 of 18 ) we observe a remarkable increase in outgrowth in the presence of the Mre11 inhibitor. This indicates that approximately one third of the breaks (P63.4, P63.7, P63.9, P63.15, and P63.18) enter an adverse repair process when they engage in DNA end-resection, whereas almost half of the breaks in this set of 18 (P63.1, P63.3, P63.5, P63.6, P63.8, P63.11-14, and P63.16) critically depend on DNA end-resection to reduce their detrimental effects on cell proliferation. Additionally, for a smaller subsef of these breaks P63.2, P63.10, and P63.17) the absence of DNA endresection does not seem to affect the outcome of the damage response.

To validate the findings of the clonogenic assays, we generated growth curves for all $18 \mathrm{gRNAs}$ in the absence or presence of DNA-PKi or Mre11i (Suppl. Fig. 2B, C). We next selected one break site for which inhibition of end-resection decreased proliferation (P63.1) and one break site for which inhibition of end-resection improved proliferation (P63.4), and analyzed growth rates following break formation. Both P63.6 and P63.4 treated cells displayed a decreased proliferative capacity when c-NHEJ was blocked (DNA-PKi), whereas proliferation of cells treated with P63.6 decreased upon inhibition of DNA endresection (Fig. 2I), while the cells treated with $P 63.4$ performed much better upon inhibition of DNA endresection. We find that eventually proliferative capacity is restored in all cultures, which could imply that break sites that produce the strongest growth inhibition produce a much longer cell cycle arrest. Thus, these data do show that location-specific DNA repair preferences play a considerable role in the overall effect of a single DNA break on cell proliferation.

Next, we wondered what could cause the proliferative arrest induced by these single DSBs. Since the proliferative arrest after $\gamma$-irradiation is dependent on p53 (Suppl. Fig. 2D), we reasoned that p53 loss 
might be able to overcome the inhibition of cell proliferation after Cas9-induced single break formation. Therefore, we compared the inhibition of cell proliferation in wild-type and p53-deficient cells challenged with a single break, using one site (P63.4) for which end-resection proved to be deleterious in wild-type cells and a single site (P63.6) for which end-resection was beneficial (Fig. 2J). We find that both these breaks perturb proliferation to some extent, but the reduction in proliferation is more pronounced in wildtype cells suffering from a P63.4-induced break, as compared to a P63.6-induced break. Importantly, both P63.4- and P63.6-induced breaks do not inhibit proliferation in cells which are deficient for p53. This indicates that the proliferative disadvantage that cells experience following break formation with P63.4 in wild-type cells is caused by p53 transcriptional responses.

To test this notion, we compared the inhibition of cell proliferation of cells challenged with a single break, using the 18 unique gRNAs in both WT and TP53/- cells. In order to determine the effect of a single break on the proliferative capacity of cells, we averaged all the growth curves of each single cutting gRNA (P63.1-P63.18) containing cells (Suppl. Fig, 2E). We observe a reduction of proliferation in the wild-type cells challenged with single-cutting gRNAs compared to control, whereas the TP53- ${ }^{-}$cells are not hampered in their proliferation when challenged with a single DNA break.

Break location dictates the extent of resection through H4K20 di-methylation levels, 53BP1, and the $\underline{\text { Shieldin complex }}$

Classically, the inhibition of DNA repair pathways has been associated with decreased cell survival| ${ }^{45,49}$. Indeed, the inhibition of Mre11 or DNA-PKcs can perturb colony outgrowth in $\gamma$-irradiated cells (Suppl. Fig. 1F). Therefore, we were intrigued by the improved cell survival that we observed for a subset of DNA breaks when engaging in DNA end-resection. To address this, we monitored the effect of each individual gRNA on cellular proliferation. Surprisingly, the cellular response to the individual breaks was highly heterogeneous, ranging from very short to a very prolonged delay in cell proliferation (Fig.3A, B). Eventually, proliferative capacity is restored in all cultures, but given that not all cells suffer from a Cas9induced break (based on targeted indel sequencing, Suppl. Fig. 2A), this could be due to overgrowth of a population of cells in which a break never occurred. Interestingly, we observe that cells exposed to breaks, whose survival improves upon the inhibition of DNA end-resection (Fig. 2H, Mre11i), tend to proliferate less 
compared to other breaks (Fig.3A, B, Suppl. Fig. 2F). Conversely, cells exposed to breaks that depend on DNA end-resection for their repair (Fig.2H, Mre11i) are less affected. Based on this notion, we subdivided breaks into "GO" breaks (those that benefit from end-resection) and "HALT" breaks (those that become toxic when engaging in end-resection) (Fig. 3C).

We have recently shown that DNA breaks undergoing DNA end-resection can convert into a lesion which permanently removes cells from the division cycle ${ }^{50}$. However, it remained unclear how and why deleterious DNA end-resection was caused by these breaks. Therefore, we wondered whether we could use our newly discovered class of "HALT" breaks to answer this question. To test this, we induced 4 breaks, two "GO" (P63.1 and P63.6) and two "HALT" (P63.4 and P63.7) breaks and quantified the prevalence and extent of DNA end-resection (Fig. 3D-G). We observed that DNA end-resection was more prevalent on "HALT" breaks compared to "GO" breaks (Fig. 3F). In addition, we found that the extent of DNA endresection on "HALT" breaks is higher compared to "GO" breaks (Fig. 3G). Thus, not only does DNA resection occur more often on "HALT" breaks, but also the extent of DNA end-resection is increased.

Next, we wondered whether the extensive DNA end-resection ${ }^{51}$ would lead to problematic DNA repair. Therefore, we monitored the presence of DNA breaks at early and late time points in cells containing "HALT" (P63.4 and P63.7) and "GO" (P63.1 and P63.6) breaks (Fig. 3H). We observe no difference in the induction (8hrs) of DNA breaks at early timepoints between "HALT" and "GO" breaks. However, we do observe a striking difference in the clearance of DNA breaks when we allow time for DNA repair (24hrs) between "HALT" and "GO" breaks. The "HALT" breaks do not appear to complete DNA repair, whereas the" GO" breaks can be repaired within this time window (Fig. 3H, dotted line). This indicates that extensive end-resection results in reduced DNA repair speed.

We reasoned that the high activity of DNA end-resection and problematic repair could be caused by a lack of the 53BP1 inhibitory effects on resection. The recruitment of 53BP1 to DSBs is mediated by the cooperative binding to two histone modification, ubiquitination of Lys15 on Histone $\mathrm{H} 2 \mathrm{~A}$ and dimethylation on Histone H4 on Lys20 ${ }^{52-54}$. Therefore, we induced "HALT" and "GO" breaks and stained the cells for $\mathrm{H} 4 \mathrm{~K} 2 \mathrm{Ome} \mathrm{m}_{2}$ and $\gamma \mathrm{H} 2 \mathrm{AX}$ in combination with EdU. In order to rule out previously described cell cycle effects on $\mathrm{H}_{4} \mathrm{~K}_{2} \mathrm{Ome} \mathrm{m}_{2}$ levels ${ }^{48}$, we selected G2 phase cells based on the absence of EdU and high DAPI signal ${ }^{50}$. In these cells, we quantified the intensity of $\mathrm{H}_{4 \mathrm{~K} 2} 2 \mathrm{me}_{2}$ levels at the $\gamma \mathrm{H} 2 \mathrm{AX}$ focus. We find that the 
HALT breaks occur in areas with lower levels of H4K20me2 compared to GO breaks (Fig 3I, Suppl. Fig. $2 \mathrm{G})$. This indicates that the breaks, which undergo extensive resection, occur in regions with lower levels of $\mathrm{H} 4 \mathrm{~K} 2 \mathrm{Ome}$ following the induction of the DSB. To further corroborate this notion, we induced a "HALT" (P63.7) and a "GO" break (P63.6) and assayed the recruitment of 53BP1 by means chromatin immunoprecipitations (Fig. 3J). We find that the recruitment of 53BP1 proximal (1 kb and 5kb) to the DSB is not altered comparing a "HALT" versus "GO" break. Nonetheless, 53BP1 is present at the same low levels as in non-damaged DNA at the distal (10kb and 50kb) regions of "HALT" breaks but not at "GO" breaks. This suggests that due to low levels of H4K20me, the spreading of 53BP1 is impaired at "HALT" breaks, which allows extensive DNA end-resection resulting in impaired proliferation.

We have shown that a subset of DNA break engages in extensive DNA end-resection and that these repair events dramatically reduce cellular proliferation. Therefore, we reasoned that if we could steer the preferred repair pathway from DNA end-resection towards C-NHEJ at these "HALT" sites, we should be able to alleviate negative effects on cell proliferation. In order to steer repair pathway preference, we made use of a fusion protein consisting of the FHA-domain of RNF8 and the OB-fold domains of Shieldin2 (FHASHLDN2-OB ${ }^{W T}$, Suppl. Fig. $2 \mathrm{H}$ ). This fusion protein is recruited at every break, through the FHA domain, which allows for recruitment of the Shieldin complex in a 53BP1-independent manner ${ }^{20}$, and inhibition of exonuclease-mediated DNA end-resection by means of its OB-fold domain (Fig. 3K) ${ }^{20}$. Consistent with our earlier findings (Fig. 3H), we observe in wild-type condition that the breaks which induce extensive DNA end-resection ("HALT", P63.4 and P63.7) are greatly reduced in their proliferation compared to our control breaks ("GO", P63.1 and P63.6) (Fig. 3L). Importantly, expression of the FHA-SHLDN2-OBWT can revert the toxic effects of the "HALT" breaks, but it does not affect proliferation in cells exposed to the "GO" breaks. Conversely, the expression of an FHA-SHLDN2-OB mutant, which is unable to bind to sSDNA and inhibit exonucleases $^{20}$, does not increase proliferation of cells challenged "HALT" breaks (P63.4 and P63.7). These data show that the failure to recruit 53BP1 and Shieldin at regions surrounding breaks is the cause for their toxicity.

Taken together, these data imply that toxic breaks can be produced by end-resection in regions that are devoid of di-methylation on Histone H4 Lysine 20 resulting in reducing 53BP1 levels. Improper recruitment of this pathway leads to extensive resection, which in turn results in problems in clearing these 
DNA breaks. Ectopic recruitment of the Shieldin2 OB-fold, known to block DNA end-resection ${ }^{20}$, rescues viability and proliferation of cells challenged with extensively resected DNA breaks.

\section{Highly accessible chromatin enables extensive DNA end-resection}

Our data thus far show that proliferative capacity in response to DNA end-resection activities varies across different sites in the genome. Next, we wanted to identify the responsible factors. Given the prior evidence that the chromatin state can affect repair pathway choice $26,28,39,40$, we set out to generate a map of the epigenome of RPE-1 hTERT cells by means of ChIP-sequencing. To this end, we analyzed the genomewide profiles of histone modifications $\mathrm{H} 3 \mathrm{~K} 36 \mathrm{me} 3$ (active gene bodies), $\mathrm{H} 3 \mathrm{~K} 4 \mathrm{me} 3$ (active promoter), H3K4me1 (active enhancers), H3K9me3 (heterochromatin) and H3K27me3 (Polycomb repressed) (Suppl. Fig. 3). Using by chromHMM ${ }^{55}$, we integrated the histone mark ChIP-seq data, revealing distinct chromatin states (Suppl Fig 4A), which were subsequently overlaid with DNA end-resection dependence. However, we failed to identify a clear correlation between a particular chromatin state and extensive DNA endresection (Suppl. Fig.4A, B). We did observe that several "HALT" breaks (P63.4 and P63.7) are located in regions high in $\mathrm{H} 3 \mathrm{~K} 4 \mathrm{me} 1 / 3$ methylation plus ChromHMM states associated with active promoters and enhancers (Suppl. Fig. 4B). Indeed, most "HALT" breaks are in closer proximity to H3K4-methylated chromatin compared to "GO breaks" (Suppl. Fig. 4C).

H3K4-methylated chromatin is found at active promoters and enhancers, with defining features its highly dynamic nature and accessibility compared to other chromatin domains ${ }^{56,57}$. This high level of accessibility allows transcription factor binding and loading of RNA polymerases ${ }^{57}$. Since H3K4-methylated chromatin and highly accessible chromatin are highly correlated, we wondered whether the "HALT" breaks are present in chromatin regions with higher accessibility compared to "GO" breaks. Therefore, we quantified the DNAsel hypersensitivity signal, as a readout for open chromatin, surrounding both "GO" and "HALT" breaks (Fig. 4A). We find that there is hardly any open chromatin surrounding (40kb) "GO" breaks compared to the "HALT" breaks (Fig. 4B). These data indicate that the "HALT" breaks are located in, or in close proximity of highly dynamic and accessible chromatin. This implies that the open chromatin state is permissive for extensive DNA end-resection. 
In order to determine whether the open chromatin state is permissive to extensive DNA endresection, we set out to specifically switch the chromatin state surrounding a break from an open to a closed conformation. We used a nucleolytically inactive Acidoaminococcus Sp. Cas12a (dAsCas12a) fused to a KRAB domain, which compacts nascent chromatin by means of $\mathrm{H} 3 \mathrm{~K} 9$ tri-methyl deposition and removal of histone $\mathrm{H} 3$ acetylation $(\mathrm{H} 3 \mathrm{ac})^{58}$. In order to functionally test the dAsCas12a-KRAB cell line, we used an integrated SFFV-promoter driven eGFP-NLS in the absence and presence of two synthetic gRNAs targeting this promoter (Suppl. Fig. 4D). We observed that the levels of eGFP drastically decrease following the recruitment of dCas12a-KRAB to the SFFV promoter. This indicates that our dCas12a-KRAB is functional and can be used as a tool to compact open chromatin regions.

To corroborate our hypothesis that open chromatin conformation facilitates extensive resection and toxic DNA break formation, we set out to locally compact chromatin prior to the induction of a "HALT" break (i.e. P63.7). Therefore, we made use of the combination of five independent gRNAs to recruit dCas12aKRAB to the P63.7 locus (Fig. 4C). Upon the compaction of the chromatin surrounding the P63.7target site by dCas12a-KRAB (Fig. 4D, magenta bars), we observe an increase in cell viability when cell experience the Cas9-induced P63.7 break compared to non-epigenome-edited conditions (Fig. 4D, grey bars, empty and SFFV).

We wanted to address whether the effects of chromatin state on DNA end-resection activity and cell proliferation are shared throughout the genome or intrinsic to the previously used break locations (P63.1-18). Therefore, we designed three gRNAs in close proximity to open chromatin ( 3kb), all of which target near the 3 ' of the USP36 gene locus (Fig.4E). In parallel, we designed 3 gRNAs, each targeting a

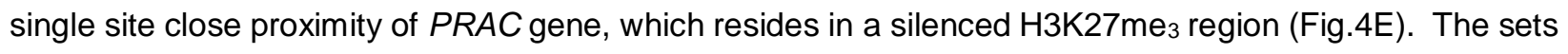
of 3 were chosen in close proximity to one another (100bp window), none of these gRNAs targets coding or predicted regulatory sequences. Using these gRNAs, we could observe approximately one DSB above background for each gRNA plus similar targeting efficiency as assayed with TIDE (Suppl. Fig. 4E, F).

Next, we addressed whether breaks in close proximity to USP36 (open chromatin) decreased cell viability (Fig. 4F, Suppl. Fig 4G). Indeed, we observe that USP36 breaks decrease cell viability, whereas breaks in the vicinity of PRAC (closed chromatin) does not affect cell viability. In addition, we addressed the influence of DNA end-resection on the decreased cell viability by depleting Mre11 (Fig. 4F, Suppl. Fig 
4G). We observed increased cell viability by depleting Mre11 in cells targeted with USP36-proximal DSBS classifying them as "HALT" breaks, but we did not observe an effect on cell viability with DSBs in the vicinity of PRAC. These data strongly suggest that the detrimental effects of DNA end-resection in open chromatin are shared throughout the genome.

The USP36-proximal DSBS do not occur directly within the open chromatin domain but approximately $3 \mathrm{~kb}$ upstream. We, therefore, wondered if removal of the proximal open chromatin domain would neutralize the toxicity of the USP36-proximal DSBs. Therefore, we designed two gRNAs to excise the $12 \mathrm{~kb}$ open chromatin region, which contains two clusters of DNAsel hypersensitive peaks (Fig. 4G, Left) Following genome editing, we derived two clones (\#8 and \#22) lacking the open chromatin domain as validated by multiple PCRs on genomic DNA plus Sanger sequencing of the fusion product (Fig. 4G - Right, Suppl. Fig. 4H). Next, we addressed whether the loss of this genomic region reduced the detrimental effects of a USP36-proximal DSB (Fig. 4H). Indeed, we observe that the proliferative capacity of both of our clones, \#8 and \#22, is not affected when USP36-proximal breaks are introduced. Thus, we can neutralize the toxicity of a "HALT" site by removal of the proximal open chromatin, essentially turning it into a "GO" site.

Taken together, we have assessed the role of the chromatin state near a DSB site using two orthogonal approaches. We compact open chromatin using dCas12A-KRAB and alternatively remove a region of open chromatin near USP36 via genome engineering. Both strategies show that open chromatin in proximity to a DSB permits extensive DNA end-resection and negatively influences cell viability.

\section{Vorinostat acts as a radiosensitizer by opening chromatin and enabling extensive DNA end-} resection

Up till now, we have described that open chromatin permits extensive DNA end-resection on nascent DSBs through the inability to properly recruit 53BP1 and the Shieldin complex. Inhibition of HDACs was shown to increase histone acetylation levels as well as chromatin accessibility ${ }^{59}$. Therefore, we reasoned that radio-sensitization by HDAC inhibitors could be the result of the creation of more accessible chromatin, leading to more extensive DNA end-resection. In order to test this hypothesis, we treated RPE1 cells for 24 hours with the FDA-approved HDAC inhibitor, vorinostat. Upon treatment, we observed a 
striking increase in the level of acetylation of Histone H3 (Fig. 5A). Concomitantly, we found an increase in nuclear size plus a decrease in pixel-to-pixel variation of DAPI intensity (Fig. 5B), which has previously been linked to chromatin decondensation ${ }^{60}$. These 24 -hour treatments of vorinostat do not alter proliferative capacity (Suppl. Fig. 5A) nor did it display increased levels of DNA damage as measured by $\gamma \mathrm{H} 2 \mathrm{AX}$ foci (Suppl. Fig. 5B)

In order to show that HDAC inhibitor-treated cells alter their repair pathway preference towards DNA end-resection, we stained control and vorinostat-treated cells for RPA and 53BP1 following 2 Gray of $\gamma$-Irradiation. We assume that opening up of chromatin in vorinostat-treated cells results in more limited 53BP1 foci following $\gamma$-Irradiation. Indeed, we find that 53BP1 loading is decreased in cells pre-treated with HDAC inhibitor compared to control treated cells (Fig. 5C).

As expected, we find that vorinostat drastically decreasescell viability with increasing doses of $\gamma$ irradiation (Fig. 5D, left graph). However, the observed radiosensitivity is lost upon expression of FHASHLDN2-OB ${ }^{W T}$ (Fig 5D right graph). This indicates that inhibition of DNA end-resection alleviates the vorinostat-induced radio-sensitization. In line with previous observations (Fig 2J), the radiosensitizing effect of vorinostat is present in WT, but not in p53-deficient cells (Fig. 5E). This shows that the loss in cell viability is, at least in part, dependent on p53 transcriptional responses.

Previous studies have described retention of DNA damage during DNA repair in cells pre-treated with HDAC inhibitors. Unexpectedly, we do not find a difference in repair capacity in WT cells pre-treated with vorinostat (Fig. 5F). Strikingly, when we perform these experiments in FHA-SHLDN2-OB ${ }^{\mathrm{WT}}$ expressing cells, there is a dramatic decrease in the number of $\gamma \mathrm{H} 2 \mathrm{AX}$ foci upon pre-treatment of vorinostat. This indicates that the presence of vorinostat shifts DNA repair towards DNA end-resection, which is reverted to a preference for c-NHEJ upon expression of the FHA-SHLDN2-OB ${ }^{W T}$ fusion.

Thus, opening up of chromatin by vorinostat leads to an increase of DNA end-resection by lack of proper 53BP1 recruitment. These changes in repair pathway usage radio-sensitizes wild-type cells. Upon expression of FHA-SHLDN2-OBWT, the radio-sensitization effects of Vorinostat are lost.

\section{Discussion}


In this study, we describe the differences in DNA repair pathway preferences at diverse DNA DSBs. We find that a subset of breaks is poorly tolerated by RPE-1 cells when they engage in DNA end-resection. We show that these breaks have difficulties recruiting 53BP1 and its downstream effectors, the Shieldin complex. Combining the break sites and epigenome data, we find that the detrimental DNA end-resection occurs in regions with high accessibility of chromatin, marked by DNAsel hypersensitivity peaks. In addition, condensation or excision of proximal open chromatin regions neutralized toxic effects caused by DNA endresection (Fig. 6). Finally, we show that the previously described HDAC inhibitor-induced radio-sensitization is mediated through DNA end-resection.

A caveat of this study is the use of Cas9 as a tool to induce DNA breaks. Previous studies have shown that Cas9 tends to stick to the break following cleavage ${ }^{61}$. Therefore, the DNA end chemistry of these DSBs does not completely resemble $\gamma$-Irradiation breaks but rather resembles Topoisomerase IIinduced breaks ${ }^{3}$. However, it also brings many advantages such as immense targeting flexibility compared to $\gamma$-irradiation. We did manage to corroborate our findings on the toxic effect of engaging end-resection in open chromatin using a combination of vorinostat and $\gamma$-irradiation. Hence, we reason that the use of Cas9 in such experiments is an unfavorable but inevitable trait to study location-dependent effects on the DNA damage response.

Chromatin remodeling has been associated with the activity of multiple repair processes. In terms of DNA end-resection chromatin remodeling is required to open up chromatin to allow CtIP-dependent resection ${ }^{62,63}$. One such chromatin remodeler, SRCAP, is essential for CtIP-dependent long-range DNA end-resection ${ }^{64}$. Interestingly, the loss of SRCAP could be compensated with the treatment of chromatinrelaxing compounds (e.g. sodium-butyrate or chloroquine). These data are in line with our findings, which suggest a positive influence of open chromatin in promoting DNA end-resection. This raises the question whether enhancers and promoters even require remodeling of the chromatin to induce DNA end-resection and HR.

In order to induce crossovers during meiosis, Spo11-induced DNA DSBs are required to initiate meiotic recombination, a process similar to homologous recombination. Interestingly, the Spo11-mediated induction of DNA DSBs during meiosis are restricted to regions high in $\mathrm{H} 3 \mathrm{~K} 4 \mathrm{me}$. This might be due to specific requirements of Spo11 towards open and relaxed chromatin ${ }^{65}$. Alternatively, Spo11 might be 
directly targeted $\mathrm{H} 3 \mathrm{~K} 4 \mathrm{me} 3$ chromatin mark, which is more prone to engage in extensive DNA end-resection compared to the rest of the genome. This would confer the meiotic recombination machinery more extensive templates to induce crossovers. Furthermore, VDJ-recombination and class-switch recombination have been shown to be critically dependent on H3K4-methylation ${ }^{66}$. These findings, in light of our results, could implicate open chromatin in promoting recombination events.

It has been extensively shown that a variety of mutational (repair) processes shape cancer genomes ${ }^{67}$. Analysis and characterization of these mutational processes have mainly focused on single nucleotide polymorphisms in coding sequences ${ }^{68}$. Recently, the Meyerson lab has described a surprising clustering of indels at promoters and DNAsel sites in whole-genome sequencing (WGS) of cancer patient samples $^{69}$. The bulk of the indels in these samples consisted out of long deletions implicating DNA endresection driven alternative end-joining. The location of these indels (i.e. DNAsel sites) is in line with independent estimates of DNA break prevalence in K562 cells based on DNA break detection by deepsequencing in combination with ENCODE profiles ${ }^{70}$. In addition, ER $\alpha$-dependent transcriptional activation causes the formation of R-loops (an RNA:DNA hybrid), which are processed and decay into DNA breaks ${ }^{71}$. Strikingly, the formation of R-loops mainly arises in promoters due to transcriptional pausing of RNA polymerase $\mathrm{II}^{72}$. Therefore, the formation of these promoter-associated R-loops and associated DSBs could be a central cause for the generation of these indels. There are many aspects of indel formation in cancer genomes, most of which are very poorly understood and much work still needs to be done. Therefore, we envision the role of open chromatin-associated DNA end-resection in these DNA DSBs-associated mutational processes.

\section{Acknowledgments}

The Dutch Cancer Foundation (KWF; NKI 2014-6787) and Top-Go ZonMw (91210065) funded this research. We thank Michiel Boekhout (University Medical Centre Utrecht) for critical reading of the manuscript and Bas van Steensel and Ruben Schep (Netherlands Cancer Institute) for advice. We thank all Medema, Rowland and Jacobs lab members for the helpful discussions on this study. 


\section{Author contributions}

J.vd.B. and R.H.M. conceived and designed the experiments, and wrote the paper. J.vd.B., Le.K., Li.K., R.K., A.G.M., and F.M.F.. performed the experiments and analyzed the data. S.J. Y.K. and W.Z. performed, analyzed and consulted on ChIP-sequencing data. B.vd.B. and K.J. designed macro's for microscopy analysis and assisted with the experimental setup.

\section{Conflict of interest}

The authors declare that they have no conflict of interest

\section{Figure Legends}

\section{Figure 1 - Repair pathway preference depend on genomic location and control cellular fitness}

A - An ideogram of the humangenome indicating gRNA targeting locations $\mathrm{B}-53 \mathrm{BP} 1$ and $\gamma \mathrm{H} 2 \mathrm{AX}$ costaining of tracrRNA, P46 or $P 63$ transfected cells, labeled with DAPI for nuclear staining (scale bar $=5 \mu \mathrm{m}$ ). C - Quantification of 53BP1 and $\gamma \mathrm{H} 2 \mathrm{AX}$ foci per nucleus in the absence and presence of gRNAs and Cas9. $(n=3$ independent experiments, error bar $=S D) D-p S e r 2056$ DNA-PKcs and $\gamma H 2 A X$ co-staining of tracrRNA, P46 or P63 transfected cells counter-stained with DAPI (scale bar $=5 \mu \mathrm{m})$. E - The percentage of pSer2056 DNA-PKcs positive $\gamma \mathrm{H} 2 \mathrm{AX}$ foci (colocalization) in cells treated as in (D). ( $n=3$, mean, error bars represent SD). F - Co-staining of RAD51 and $\gamma \mathrm{H} 2 \mathrm{AX}$ in tracrRNA, P46 or P63 transfected cells counterstained with DAPI (scale bar $=5 \mu \mathrm{m}) . \mathrm{G}-$ The percentage of RAD51 positive $\gamma \mathrm{H} 2 \mathrm{AX}$ foci in cells treated as in $(F)$. ( $n=3$, mean, error bars represent SD). $H$ - cartoon depicting the initial steps of DNA repair and the competition between c-NHEJ and DNA end-resection. I - Analysis of insertions and deletions by means of TIDE of cells targeted with the HS1a gRNA in the absence and presence of DNA-PKi $(1 \mu \mathrm{M})$ or Mre11i $(12.5 \mu \mathrm{M})(\mathrm{n}=2$, error bar $=\mathrm{SD}) . \mathrm{J}-$ Clonogenic outgrowth in gRNA transfected cells (tracr, $P 46, P 63)$ in the presence of DMSO, $(1 \mu \mathrm{M})$ or Mre11i $(12.5 \mu \mathrm{M})(\mathrm{n}=3$, error bars represent SEM). K - Survival in gRNA transfected cells (tracr, P46, P63) with knockdowns for DNA-PKcs or Mre11 ( $\mathrm{n}=3$, error bars represent 
SEM). L - RPE-1 iCut cells treated with indicated gRNAs and inhibitors, which were fixed 24 hours following transfection and inhibitor treatment. Quantification of $\gamma \mathrm{H} 2 \mathrm{AX}$ foci per nucleus in the presence of indicated gRNAs and inhibitors. ( $n=3$ independent experiments, (mean, error bar $=S D$ )

Figure 2 - A subset of breaks are detrimental for cellular proliferation upon activation of DNA endresection

A - Cartoon depicting the design for the 18 single cutters (pool) relative to P63. DNA damage induction with 18 individual single cutters assayed by 53BP1 foci per nucleus (minimally 500 cells, error bar represents SD). B - 53BP1 and $\gamma \mathrm{H} 2 \mathrm{AX}$ co-staining of tracrRNA, pool or P63 transfected cells, labeled with DAPI for nuclear staining (scale bar $=5 \mu \mathrm{m})$. C - Co-staining of pSer2056 DNA PKcs and $\gamma \mathrm{H} 2 \mathrm{AX}$ in P63pool or P63 transfected cells counter-stained with DAPI (scale bar $=5 \mu \mathrm{m}$ ). D - Co-staining of RAD51 and $\gamma \mathrm{H} 2 \mathrm{AX}$ in tracrRNA, P46 or P63 transfected cells counter-stained with DAPI (scale bar $=5 \mu \mathrm{m}$ ). E Quantification of the percentage RAD51 or pSer2056 DNA-PKcs positive $\gamma \mathrm{H} 2 \mathrm{AX}$ foci (colocalization). (cells were analyzed from three independent experiments, error bars = SD) F - Clonogenic outgrowth of gRNA transfected cells (tracr, P63pool, P63) in the presence of DMSO, DNA-PKi or Mre11i $(n=3$, error bars $=$ SEM). G - Clonogenic outgrowth of gRNA transfected cells (tracr, P63pool, P63) with knockdowns for DNAPKcs or Mre11 $(n=3$, error bars $=$ SEM). $H-$ Clonogenic outgrowth of gRNA transfected cells (tracr only or P63.1 through P63.18) in the presence of DMSO, DNA-PKi or Mre11i $(n=3$, error bars $=S D)$. $C$ - Example growth curves of RPE-1 iCut cells transfected with P63.4 and P63.6 in the presence of DMSO, DNA-PKi or Mre11i $(n=3$, error bar $=$ SD). J - Growth curves of RPE-1 iCut cells (WT and TP53-- ), transfected with the P63.4 and P63.6 gRNAs (Mean of two independent experiments, error bars = SD).

Figure 3 - Break location dictates the extent of resection mediated by H4K20me2-53BP1-Shieldin complex

A - Growth curves of RPE-1 iCut cells transfected with tracrRNA only (black line) or 18 individual gRNAs (separated in resection beneficial (green color) and resection deleterious (orange color)). Mean of three independent experiments. B - Quantification of the fold increase in cell number at 120 hours post- 
transfection compared to start of imaging, of cells in (Fig. 3A). C - cartoon depicting two classes of DNA breaks in term of their response towards the activation of DNA end-resection. "HALT" breaks are locations that provoke a detrimental DNA damage response upon activation of DNA end-resection. "GO" breaks require the activity of DNA end-resection to limit detrimental effects of DNA damage responses D - Costaining of RPA and $\gamma \mathrm{H} 2 \mathrm{AX}$ in G2 cells (DAPI high, EdU) cells transfected (8hr) with "GO" breaks P63.1 or P63.6 (scale bars $=5 \mu \mathrm{m}$ ). E - Co-staining of RPA and $\gamma \mathrm{H} 2 \mathrm{AX}$ in G2 cells (DAPI high, EdU-) cells transfected (8hr) with "HALT" breaks $P 63.4$ or $P 63.7$ (scale bars $=5 \mu \mathrm{m}$ ) F - Quantification of the percentage of cells bearing RPA $+\gamma \mathrm{H} 2 \mathrm{AX}$ foci $(\mathrm{n}=3$, mean, errors bars = SD) $\mathrm{G}-$ Quantification RPA density (size*intensity) of $\mathrm{RPA}^{+} \gamma \mathrm{H} 2 \mathrm{AX}$ depicted in Fig. 3F. $\mathrm{H}$-Immunofluorescence quantification of $\mathrm{H} 4 \mathrm{~K} 2 \mathrm{Ome}$ levels at the $\gamma \mathrm{H} 2 \mathrm{AX}$ focus in cells transfected (8hrs) with indicated gRNAs. I-53BP1 ChIP-qPCR at indicated distance from the respective gRNA induced DNA DSB transfected with either on-target gRNA (P63.6 or P63.7) or tracrRNA $(n=2$, error bars $=S D) J-Q u a n t i f i c a t i o n$ of 53BP1 foci at 8- and 24-hours following transfection of gRNAs inducing breaks that do (P63.1 and P63.6) and do not (P63.4 and P63.7) displaying toxicity in the presence of DNA end-resection activity (dashed lines indicate the average number of background foci in untreated control RPE-1 hTERT cells). K - Cartoon depicting the recruitment and action of the FHASHLDN2-OB ${ }^{W T}$. L - Clonogenic outgrowth of gRNA transfected cells "GO" (P63.1 or P63.6) or "HALT" (P63.4 or P63.7) in iCut WT, iCut FHA-SHLDN2-OB ${ }^{W T}$ or FHA-SHLDN2-OB ${ }^{M U T}(n=3$, error bars $=S D)$.

\section{Figure 4 - Highly accessible chromatin enables extensive DNA end-resection}

A - Average DNAsel hypersensitivity signal over either all "GO" $(n=7)$ or "HALT" $(n=11)$ breaks 40kb window surrounding break site (track of the DNAsel average signal and standard deviation, 40kb) B - The number of overlapping DNA fragments from two DNAsel replicates from RPE-1 hTERT cells were counted within an area ranging from the center of the regions in the "HALT" or "GO" with an offset of $20 \mathrm{~kb}$ to center of the regions. Quantities were normalized to a dataset size of one million reads and normalized to an area size of $1000 \mathrm{bp} . \mathrm{C}-$ Track of DNAsel hypersensitivity of $4 \mathrm{~kb}$ surrounding the site of the P63.7 break (orange) with indicated gRNAs (pink) for dAsCas12a-KRAB. D - RPE-1 iCut dAsCas12a-KRAB cells were transfected indicated Cas12a gRNAs. Forty-eight hours later cells were challenged with P63.7 with or without activation of iCut (Cas9). Subsequently, these cells were plated for clonogenic assay and quantified 


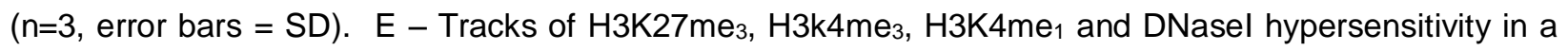
$100 \mathrm{~kb}$ window surrounding a 100bp window Cas9-induced breaks ( 3 independent gRNAs) for both the USP36 and PRAC locus. F - Clonogenic outgrowth of PRAC or USP36 targeted in control-depleted cells or Mre11-depleted RPE-1 iCut cells ( $n=3$, error bars - SD). G - (Left) Depiction of USP36 locus surrounding the DNAsel hypersensitive and USP36 gRNA sites. (Right) Genome edited cells lacking the CYTH1 enhancer and promoter region proximal to the USP36-associated breaks. (Right) Genomic DNA PCR validating two independently derived monoclonal cell lines, \#8, and \#22. H-Clonogenic assay of RPE iCut or enh.CYTH1 $\# 8$ or \#22 transfected with gRNA targeting USP36 (open chromatin) or PRAC (closed chromatin) ( $n=3$, error bars $=S D)$.

Figure 5 - Vorinostat open up chromatin and enable extensive DNA end-resection

A - Quantification of Histone H3 acetylation levels in RPE-1 iCut cells treated with DMSO or Vorinostat $(1 \mu \mathrm{M})$ for 24 hours. B - Quantification of pixel-to-pixel variation of DAPI signal in RPE-1 iCut cells treated with DMSO or Vorinostat $(1 \mu \mathrm{M})$ for 24 hours. C - Quantification of 53BP1 nuclear foci in cells DMSO or Vorinostat pre-treated cells fixed at indicated times following 2 Gray of $\gamma$-Irradiation. D - Clonogenic outgrowth of iCut WT or FHA-SHLDN2-OB ${ }^{\text {wt }}$ cells pre-treated with $1 \mu \mathrm{M}$ vorinostat (24hrs), with increasing doses of $\gamma$-irradiation. E - Clonogenic outgrowth of iCut WT or TP53 ${ }^{-}$cells pre-treated with $1 \mu \mathrm{M}$ vorinostat (24hrs), with increasing doses of $\gamma$-irradiation E - Quantification of $\gamma \mathrm{H} 2 \mathrm{AX}$ nuclear foci in DMSO or Vorinostat pre-treated cells (iCut WT and FHA-SHLDN2-OB ${ }^{\mathrm{WT}}$ ) fixed 4 hours following 2 Gray of $\gamma$ Irradiation.

Figure 6 - Deleterious DNA end-resection is permitted in highly accessible chromatin due to the lack of H4K20me2-53BP1-Shieldin

Our model describing how the activation of DNA end-resection on DSB in proximity to open chromatin results in a detrimental DNA damage response by improper recruitment of 53BP1 and Shieldin complex.

\section{Suppl. Fig. 1 - Toxic repair intermediates by DNA end-resection on a subset of breaks}


A and B-Proliferative capacity of RPE-1 iCut cells with increasing concentration of DNA-PKi $(A)$ or Mre11i (B). C and D - Mitotic entry of RPE-1 iCut FUCCI cells treated with increasing concentrations of DNA-PKi (C) or Mre11i (D). E - DNA repair products of RPE-1 iCut cells transfected with HS1b guideRNA (48 hours following transfection) in the presence of $12.5 \mu \mathrm{M}$ Mre11i and $1 \mu \mathrm{M}$ DNA-PKi. F - Clonogenic outgrowth in the presence of $12.5 \mu \mathrm{M}$ Mre11i or $1 \mu \mathrm{M}$ DNA-PKi, with increasing doses of $\gamma$-irradiation. G - Knockdown of DNA-PKcs and Mre11 in RPE-1 iCut cells transfected with the indicated siRNAs. H - Clonogenic outgrowth of RPE-1 iCut cells (WT and TP53-- ) treated with increasing doses of $\gamma$-irradiation. I - 53BP1-mCherry expressing iCut cells were transfected with GAPDHP46 or GAPDHP63 and followed by time-lapse microscopy for every 15 minutes. In each cell, the timepoint with the highest foci number was set at $\mathrm{t}=0$ and normalized to $100 \%$.

Suppl. Fig. 2 - Single breaks reveal differential repair pathway requirements and DNA damage responses

A - Identification of the percentage of disrupted alleles in RPE-1 iCut cells transfected with gRNAs targeting individual loci (P63.1 through P63.18) using TIDE analysis. B - Fold increase in cell numbers at 96 hours compared to baseline (\%) in gRNA transfected cells (tracr only or P63.1 through P63.18) in the presence of DMSO, DNA-PKi or Mre11i $(n=3$, error bar $=S D)$. $C-$ Venn diagram of DNA breaks which impair cellular proliferation in the presence of DNA end-resection, identified by clonogenic assay and growth curve

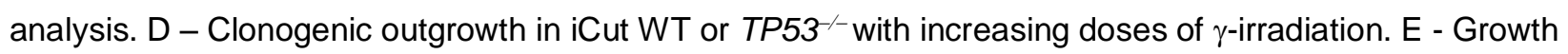
curves of RPE-1 iCut cells (WT and TP53--), transfected with individual P63.1 -p63.18 gRNAs compared to control (tracrRNA $=$ no break) (Mean of two independent experiments, error bars $=S D$ ). $F-$ Boxplot of fold increase in 96 hours proliferation of "HALT" or "GO" breaks (average from Fig. 3B). G - Example images of H4K20me $-\gamma \mathrm{H} 2 \mathrm{AX}$ co-staining in cells transfected with P63.1 ("GO") and P63.4 ("HALT") gRNAs. $\mathrm{H}$ - Western blot analysis of stable doxycycline-inducible FHA-GFP, GFP-SHLDN2(FL) and FHA-SHLDN2OB expression RPE-1 iCut cells.

\section{Suppl. Fig 3 - Epigenome analysis of RPE-1 hTERT}


Genomic locations of peaks found in both replicates for H3K4me1 H3K4me3, H3K27me3, H3K9me3 and H3K36me3 (pie-chart). Correlation of peaks called in each independent replicate for H3K4me1 H3K4me3, H3K27me3, H3K9me3 and H3K36me3 (scatterplots).

Suppl. Fig. 4 - Open chromatin permits extensive and deleterious DNA end-resection.

A - ChromHMM analysis of 10 different states of chromatin in RPE-1 hTERT cells. B - Overlay gRNA target location, "HALT" or "GO" status and ChromHMM state. C - distance from H3K4-methylated peaks in both the "HALT" or "GO" break locations. D - Repression of pSFFV-eGFP-NLS stable RPE-1 iCut dCas12aKRAB cells mock transfected or with 2 SFFV targeting Cas12a gRNAs (counts of cells, eGFP intensity). E - TIDE analysis of the efficiency of gRNAs used in Fig. 4E and 4G. F - Quantification of the number of foci at $8 \mathrm{hrs}$ following transfection of gRNAs used in Fig. $4 \mathrm{E}$ and $4 \mathrm{G}, \mathrm{G}-$ Clonogenic outgrowth of each individual gRNA in the PRAC or USP36 region in control-depleted cells or Mre11-depleted RPE-1 iCut cells $(n=3$, error bars $-S D)$. $H$ - Sanger sequencing of the fusion product (1, Fig. 4G, Right) in RPE-1 iCut enh.CYTH1 $\triangle$ \#8 and \#22 clone.

\section{Suppl. Fig. 5 - HDAC inhibitors cause opening up of chromatin and enable DNA end-resection}

A - Kill-curve of RPE iCut WT and FHA-SHLDN2-OB ${ }^{W T}$ cells with increasing concentrations of Vorinostat.

B - Quantification of $\gamma \mathrm{H} 2 \mathrm{AX}$ nuclear foci in RPE-1 iCut cells treated with DMSO or Vorinostat $(1 \mu \mathrm{M})$ for 24 hours.

\section{Materials and Methods}

\section{$\underline{\text { Cell lines, Tissue Culture, and Irradiation }}$}

Retinal pigment epithelial (RPE-1) hTERT cell lines, obtained from American Type Culture Collection, were maintained in DMEM/F12 GlutaMAX medium (Gibco) containing 10\% Tetracycline-free Fetal Bovine Serum and $1 \%$ Penicillin-Streptomycin $(10.000 \mathrm{U} / \mathrm{mL})$. RPE-1 iCut and iCut TP53 $^{-/}$cells were generated as previously described ${ }^{31}$. Shieldin2 expression constructs were a kind gift from S. Noordermeer and D. 
Durocher. Chemicals used in this study: Doxycycline (Sigma, 1mM), SHIELD-1 (Aobious, $1 \mu \mathrm{M}$ ), Nutlin-3a, DNAPKi (NU-7441, $1 \mu \mathrm{M}$, Cayman Chemicals), Mre11i (Mirin, 12,5 $\mu \mathrm{M}$, Sigma).

\section{tracrRNA:crRNA design and transfections}

Alt-R crRNA (Integrated DNA technologies) were designed with on-target scores determined by the Rule Set $2^{73}$. We selected sgRNAs based on predictions from the CRISPOR tool ${ }^{74}$. tracrRNA:crRNA duplex was transfected according to the manufacturer's protocol ${ }^{75}$.

\section{Clonogenic assays \& Colony Formation Assay}

For clonogenic assays, iCut cells were transfected with the indicated crRNAs; and 8 hours later, 250 single cells per well were seeded in 6 well plates. Cells were treated with the indicated drugs and allowed to grow out for 7 days. Plates were fixed in $80 \%$ Methanol and stained with $0.2 \%$ Crystal Violet solution. Colonies were counted and normalized to plating efficiency of the untreated control. For colony formation assays, 1000 iCut cells were plated in a 96-well plate and treated for 7 days with indicated drug concentrations. Subsequently, plates were fixed in $80 \%$ Methanol and stained with $0.2 \%$ Crystal Violet solution.

Quantification of DNasel hypersensitivity signal

DNAsel signal quantification was performed with Easeq software. DNasel hypersensitivity (ENCSR000EON) data were acquired from the ENCODE website. The number of fragments was derived from the count by dividing it with ( 1 + DNA fragment size/size of the area). The values were converted to Z-scores by calculating the genome-wide mean (5,92751637956657) and standard deviation $(41,4931980788233)$ in windows corresponding to the average sized region $(40 \mathrm{~kb})$ and calculating the Zscore as (sample - mean) / SD. Areas above $1000 \mathrm{Mb}$ or below 100 bp were set to those sizes

\section{Determination of insertions and deletion by TIDE}


Materials required for the HS1 experiment were previously described ${ }^{31}$. P46 5'ACATGTAGACCATGTAGTTG-3' and the P63 5'- AACGGGAAGCTTGTCATCAA-3' were used to induce multiple breaks in the genome. The deconvolved $P 63$ pool consists of the following gRNAs:

\begin{tabular}{|l|l|l|}
\hline name & sequence & location \\
\hline$P 63.1$ & GACACACCGTTTTGTGGCCG & chr1:117256101-117256124 \\
\hline$P 63.2$ & TGGACCAGGTAGCGATGTAG & chr7:9652362-9652385 \\
\hline$P 63.3$ & TGGCCCTAGTTCTCCCTGTA & chr1:120137064-120137087 \\
\hline$P 63.4$ & CTGAGTCACCTTCGAACCGG & chr12:6641837-6641860 \\
\hline$P 63.5$ & GACCAATGGCTGTCAGAGTG & chr1:120039257-120039270 \\
\hline$P 63.6$ & CCTGGATAATGTATAAGTAT & chr19:47059518-47059541 \\
\hline$P 63.7$ & CTACTTAAGCTGAATAACAT & chr15:64819321-64819344 \\
\hline$P 63.8$ & ACCTTAGAAATATGCATCAG & chr6:80661477-80661500 \\
\hline$P 63.9$ & TGTAGCCTAAAATACATTGG & chr11:88140066-88140089 \\
\hline$P 63.10$ & TTGGTTACCTTACAAGCCAC & chr1:52170657-521706 \\
\hline$P 63.11$ & CTGCATCCACACTAAGTGAT & chr6:135938343-135938366 \\
\hline$P 63.12$ & ACATGGGTAGAATGTTGTGG & chr20:13367562-13367585 \\
\hline$P 63.13$ & ACAGGGGTCTTACACTAAGG & chrX:39644793-39644816 \\
\hline$P 63.14$ & GGAGCAGTGCCGATAAACAG & chr6:57685280-57685303 \\
\hline$P 63.15$ & TAAAAAGTGGTTAAGGCCGA & chr18:3976050-3976073 \\
\hline$P 63.16$ & ATAGGTAATGCGAAATACTG & chr8:101560810-101560833 \\
\hline$P 63.17$ & GTGGCACCCTAGTTGGAAGG & chr6:58296981-58297004 \\
\hline$P 63.18$ & AGTGTGCTAGCTCTGCAGTC & chr5:159376051-159376074 \\
\hline
\end{tabular}

These primers were used to amplify regions containing $P 63$ pool targeted DNA:

\begin{tabular}{|l|l|}
\hline Primer Name & Sequence (5' to $\left.3^{\prime}\right)$ \\
\hline P63.1FORWARD & CCCTTTGTGGCCTATGGGAG \\
\hline P63.1REVERSE & GAGGAAGAGAGAGGCCCTCA \\
\hline P63.2FORWARD & TGAAATCCACAGCCCAAGCA \\
\hline P63.2REVERSE & AGAGACCTCAGAGAGCTGCA \\
\hline
\end{tabular}




\begin{tabular}{|c|c|}
\hline P63.3FORWARD & ATGGCAGGTTGCTTCATCCA \\
\hline P63.3REVERSE & GCTGTTTGCCAAGGAGAAGC \\
\hline P63.4FORWARD & CCAGGGATGTGGCTCAACAT \\
\hline P63.4REVERSE & ACTGTCTTCTCCCCGCAAAG \\
\hline P63.5FORWARD & TCCAGCAATCACGCTCCATT \\
\hline P63.5REVERSE & GCСТCССССАСТАТСАACAC \\
\hline P63.6FORWARD & TGACATACTGTAGTGCCAGCT \\
\hline P63.6REVERSE & GCAGTGAGCCAAGATCATGC \\
\hline P63.7FORWARD & GGAAGGAGGCTGGAGAAACC \\
\hline P63.7REVERSE & GATGTCAGGGCAGGGAATGG \\
\hline P63.8FORWARD & CCACCACCTCCACCAGAATC \\
\hline P63.8REVERSE & GCAGGGTGAAAAGGCATTCC \\
\hline P63.9FORWARD & GGGTGGCTTCCCTGGATTTT \\
\hline P63.9REVERSE & AACGAGGAGACGGAGAAGGA \\
\hline P63.10FORWARD & CTGAGGTGCCTCGTCACATT \\
\hline P63.1OREVERSE & AGGAGATGGGAGGCTCACTT \\
\hline P63.11FORWARD & AGCTGCAGACGCCATTTAGT \\
\hline P63.11REVERSE & AAAGGCTGCATCCAACCAGA \\
\hline P63.12FORWARD & CTCACAGACAAGCCCCTCAG \\
\hline P63.12REVERSE & TGGGTGCCTGTAATCCCAAC \\
\hline P63.13FORWARD & GTTTGAGGCTGAGTTCCCCA \\
\hline P63.13REVERSE & GTGTGCTGCTGCTTTTCCTC \\
\hline P63.14FORWARD & GGTCTCATGGGTCTTTGCCA \\
\hline P63.14REVERSE & AGGCAGTGAACATGGAGATCA \\
\hline P63.15FORWARD & GATGGATGGTGGTGACGGTT \\
\hline P63.15REVERSE & GCAGGGAACAGAGAACACCA \\
\hline
\end{tabular}




\begin{tabular}{|l|l|} 
P63.16FORWARD & TGTTCCTGCCTACCTCTCCA \\
\hline P63.16REVERSE & ACTGACTTCCAGACTCCACTG \\
\hline P63.17FORWARD & TCTTGGCCTCAGATCCCTCT \\
\hline P63.17REVERSE & GAGACGGGGTTTCACCATGT \\
\hline P63.18FORWARD & ACCCTTCCAAGAACCCTATGG \\
\hline P63.18REVERSE & TCAAAAGCGCCCATGTACCA \\
\hline
\end{tabular}

\section{Live-cell \& Fixed Microscopy}

Following fixation and staining, images were acquired with the use of a DeltaVision Elite (Applied Precision) equipped with a 60x 1.45 numerical aperture (NA) lens (Olympus) and cooled CoolSnap CCD camera. DNA damage foci were evaluated in ImageJ as previously described ${ }^{76}$. For live-cell imaging, a Lionheart FX automated microscope in combination with sirDNA ${ }^{77}$ staining was used to generate growth curves with a time resolution of 4 hours for a total time span of 136 hours (microscope maintained at $37^{\circ} \mathrm{C}, 5 \% \mathrm{CO} 2$ using a $4 \times$ lens and a Sony CCD, 1.25 megapixel camera with 2 times binning; BioTek). Quantification of cell number was performed by Gen5 software (BioTek).

\section{$\underline{\text { Immunofluorescence and Western Blots }}$}

For IF, cells were fixed with $3.7 \%$ formaldehyde for $5 \mathrm{~min}$ and permeabilized with $0.2 \%$ Triton-X100 for 5 min before blocking in $3 \%$ bovine serum albumin (BSA) in PBS supplemented with $0.1 \%$ Tween (PBS-T) for $1 \mathrm{~h}$. Cells were incubated overnight at $4^{\circ} \mathrm{C}$ with the primary antibody in PBS-T with $3 \%$ BSA, washed three times with PBS-T, and incubated with secondary antibody and DAPI in PBS-T with 3\% BSA for $2 \mathrm{~h}$ at room temperature (RT). Western Blot analysis was performed as previously described ${ }^{76}$. The following primary antibodies were used in this study: anti- $\gamma \mathrm{H} 2 \mathrm{AX}$ (ser139p; 05-636 Upstate, 1:500), anti-53BP1 (H300, Santa Cruz, sc-22760, 1:500), anti-Rad51 (Santa-Cruz), anti-Rad51 (Abcam) anti-pSer2056 DNAPKcs, anti-Mre11, Anti-RPA, anti-H4K20me2 The following secondary antibodies were used for western 
blot experiments: peroxidase-conjugated goat anti-rabbit (P448 DAKO, 1:2000) and goat anti-mouse (P447

DAKO, 1:2000). Secondary antibodies used for immunofluorescence and FACS analysis were anti-rabbit Alexa 488 (A11008 Molecular probes, 1:600), anti-mouse Alexa 568 (A11004 Molecular probes, 1:600). DAPI was used at a final concentration of $1 \mu \mathrm{g} / \mathrm{mL}$.

\section{ChIP-sequencing of RPE-1 hTERT cells}

Chromatin immunoprecipitations (ChIP) were performed as described previously ${ }^{78}$ with minor adjustments. For ChIP of histone marks, approximately $3.0 \cdot 10^{7}$ million cells, $50 \mu \mathrm{L}$ of Protein A magnetic beads (Invitrogen) and $5 \mu \mathrm{g}$ of antibody were used. Antibodies were H3K27me3 (Millipore 07-449), H3K36me3 (Abcam 9050), H3K4me1 (Abcam 8895), H3K4me3 (Abcam 8580), H3K9me3 (Abcam 8898) and 53BP1

(NB100-305). For ChIP-seq, samples were processed for library preparation (Part\# 0801-0303, KAPA Biosystems kit), sequenced using an Illumina Hiseq2500 genome analyzer (65bp reads, single end) and aligned to the Human Reference Genome (hg19, February 2009) using Burrows-Wheeler Aligner (bwa) version 0.5 .9 . Mapped reads were filtered based on mapping quality of 20 using samtools version 0.1 .19 . Details are available in Table 3. For segmentation and identification of distinct states across the genome, ChromHMM version 1.11 was used ${ }^{55}$. The number of states was set to 10 , and default settings were used for the other parameters.

\section{References}

1. Hoeijmakers, J. H. Genome maintenance mechanisms for preventing cancer. Nature 411, 366-74 (2001).

2. Haber, J. E. DNA recombination: The replication connection. Trends Biochem. Sci. 24, 271-275 (1999).

3. Tubbs, A. \& Nussenzweig, A. Endogenous DNA Damage as a Source of Genomic Instability in Cancer. Cell 168, 644-656 (2017).

4. De Bont, R. \& van Larebeke, N. Endogenous DNA damage in humans: A review of quantitative 
data. Mutagenesis 19, 169-185 (2004).

5. Vilenchik, M. M. \& Knudson, A. G. Endogenous DNA double-strand breaks: production, fidelity of repair, and induction of cancer. Proc. Natl. Acad. Sci. 100, 12871-12876 (2003).

6. Woodward, W. A. et al. WNT/beta-catenin mediates radiation resistance of mouse mammary progenitor cells. Proc. Natl. Acad. Sci. U. S. A. 104, 618-23 (2007).

7. Alt, F. W., Zhang, Y., Meng, F. L., Guo, C. \& Schwer, B. Mechanisms of programmed DNA lesions and genomic instability in the immune system. Cell 152, 417-429 (2013).

8. Rooney, S., Chaudhuri, J. \& Alt, F. W. The role of the non-homologous end-joining pathway in lymphocyte development. Immunol. Rev. 200, 115-131 (2004).

9. Bartkova, J. et al. Oncogene-induced senescence is part of the tumorigenesis barrier imposed by DNA damage checkpoints. Nature 444, 633-637 (2006).

10. Hustedt, N. \& Durocher, D. The control of DNA repair by the cell cycle. Nat Cell Biol 19, 1-9 (2017).

11. Panier, S. \& Durocher, D.Push back to respond better: regulatory inhibition of the DNA doublestrand break response. Nat. Rev. Mol. Cell Biol. 14, 661-672 (2013).

12. Branzei, D. \& Foiani, M. Regulation of DNA repair throughout the cell cycle. Nat. Rev. Mol. Cell Biol. 9, 297-308 (2008).

13. Haber, J. E. Partners and pathways - Repairing a double-strand break. Trends Genet. 16, 259264 (2000).

14. Rothkamm, K., Krüger, I., Thompson, L. H., Kru, I. \& Lo, M. Pathways of DNA Double-Strand Break Repair during the Mammalian Cell Cycle Pathways of DNA Double-Strand Break Repair during the Mammalian Cell Cycle. Mol. Cell. Biol. 23, 5706-5715 (2003).

15. Burma, S., Chen, B. P. C. \& Chen, D. J. Role of non-homologous end joining (NHEJ) in maintaining genomic integrity. DNA Repair (Amst). 5, 1042-1048 (2006).

16. Roy, R., Chun, J. \& Powell, S. N. BRCA1 and BRCA2: different roles in a common pathway of genome protection. Nat. Rev. Cancer 12, 68-78 (2012).

17. Escribano-Díaz, C. et al. A Cell Cycle-Dependent Regulatory Circuit Composed of 53BP1-RIF1 and BRCA1-CtIP Controls DNA Repair Pathway Choice. Mol. Cell 49, 872-883 (2013). 
18. Bunting, S. F. et al. 53BP1 inhibits homologous recombination in brca1-deficient cells by blocking resection of DNA breaks. Cell 141, 243-254 (2010).

19. Xu, G. et al. REV7 counteracts DNA double-strand break resection and affects PARP inhibition. Nature 521, 541-4 (2015).

20. Noordermeer, S. M. et al. The shieldin complex mediates 53BP1-dependent DNA repair. Nature 560, 117-121 (2018).

21. Dev, H. et al. Shieldin complex promotes DNA end-joining and counters homologous recombination in BRCA1-null cells. Nat. Cell Biol. 20, (2018).

22. Simsek, D. \& Jasin, M. Alternative end-joining is suppressed by the canonical NHEJ component Xrcc4/ligase IV during chromosomal translocation formation. Nat Struct MolBiol 17, 410-416 (2010).

23. Ceccaldi, R., Rondinelli, B. \& D'Andrea, A. D. Repair Pathway Choices and Consequences at the Double-Strand Break. Trends Cell Biol.26, 52-64 (2016).

24. Ahrabi, S. et al. A role for human homologous recombination factors in suppressing microhomology-mediated end joining. Nucleic Acids Res. 44, 5743-5757 (2016).

25. Polo, S. E. \& Jackson, S. P. Dynamics of DNA damage response proteins at DNA breaks: A focus on protein modifications. Genes Dev. 25, 409-433 (2011).

26. Aymard, F. et al. Genome-wide mapping of long-range contacts unveils clustering of DNA doublestrand breaks at damaged active genes. Nat. Struct. Mol. Biol. (2017). doi:10.1038/nsmb.3387

27. Clouaire, T. et al. Comprehensive Mapping of Histone Modifications at DNA Double-Strand Breaks Deciphers Repair Pathway Chromatin Signatures. Mol. Cell 250-262 (2018). doi:10.1016/j.molcel.2018.08.020

28. Lemaître, C. et al. Nuclear position dictates DNA repair pathway choice. Genes Dev. 28, 2450$2463(2014)$.

29. Natale, F. et al. Identification of the elementary structural units of the DNA damage response. Nat. Commun. 8, (2017).

30. Warmerdam, D. O., van den Berg, J. \& Medema, R. H. Breaks in the 45S rDNA Lead to Recombination-Mediated Loss of Repeats. Cell Rep. 14, 1-9 (2016). 
31. van den Berg, J. et al. A limited number of double-strand DNA breaks is sufficient to delay cell cycle progression. Nucleic Acids Res. 1-13 (2018). doi:10.1101/316158

32. Tsouroula, K. et al. Temporal and Spatial Uncoupling of DNA Double Strand Break Repair Pathways within Mammalian Heterochromatin. Mol. Cell 63, 293-305 (2016).

33. Cong, L. et al. Multiplex Genome Engineering Using CRISPR/Cas System. Science (80-. ). 339, 819-824 (2013).

34. Veuger, S. J., Curtin, N. J., Richardson, C. J., Smith, G. C. M. \& Durkacz, B. W. Radiosensitization and DNA Repair Inhibition by the Combined Use of Novel Inhibitors of DNA-dependent Protein Kinase and Poly(ADP-Ribose) Polymerase-1. Cancer Res. 62, 6400-6404 (2003).

35. Morgan, M. A. et al. Mechanism of Radiosensitization by the Chk1/2 Inhibitor AZD7762 Involves Abrogation of the G2 Checkpoint and Inhibition of Homologous Recombinational DNA Repair. Cancer Res. 70, 4972-4981 (2010).

36. Lawrence, T. S., Blackstock, A. W \& McGinn, C. The mechanism of action of radiosensitization of conventional chemotherapeutic agents. Semin. Radiat. Oncol. 13, 13-21 (2003).

37. Munshi, A. Vorinostat, a histone deacetylase inhibitor, enhances the response of human tumor cells to ionizing radiation through prolongation of -H2AX foci. Mol. Cancer Ther. (2006). doi:10.1158/1535-7163.mct-06-0022

38. Groselj, B., Sharma, N. L., Hamdy, F. C., Kerr, M. \& Kiltie, A. E. Histone deacetylase inhibitors as radiosensitisers: effects on DNA damage signalling and repair. Br. J. Cancer 108, 748-54 (2013).

39. Aymard, F. et al. Transcriptionally active chromatin recruits homologous recombination at DNA double-strand breaks. Nat. Struct. Mol. Biol. 21, 366-74 (2014).

40. Janssen, A. et al. A single double-strand break system reveals repair dynamics and mechanisms in heterochromatin and Euchromatin. Genes Dev. 30, 1645-1657 (2016).

41. Mighell, A. J., Smith, N. R., Robinson, P. A. \& Markham, A. F. Vertebrate pseudogenes. FEBS Lett. 468, 109-114 (2000).

42. Caron, P. et al. Non-redundant Functions of ATM and DNA-PKcs in Response to DNA DoubleStrand Breaks Article Non-redundant Functions of ATM and DNA-PKcs in Response to DNA Double-Strand Breaks. Cell Rep. 1598-1609 (2015). doi:10.1016/j.celrep.2015.10.024 
43. Massip, L., Caron, P., lacovoni, J. S. \& Trouche, D. Deciphering the chromatin landscape induced around DNA double strand breaks. Cell Cycle 9, 2963-2972 (2010).

44. Jensen, R. B., Carreira, A. \& Kowalczykowski, S. C. Purified human BRCA2 stimulates RAD51mediated recombination. Nature 467, 678-683 (2010).

45. Zhao, Y. et al. Preclinical evaluation of a potent novel DNA-dependent protein kinase inhibitor NU7441. Cancer Res. 66, 5354-5362 (2006).

46. Shibata, A. et al. DNA Double-Strand Break Repair Pathway Choice Is Directed by Distinct MRE11 Nuclease Activities. Mol. Cell 53, 7-18 (2014).

47. Dupré, A. et al. A forward chemical genetic screen reveals an inhibitor of the Mre11-Rad50-Nbs1 complex. Nat. Chem. Biol. 4, 119-125 (2008).

48. Pellegrino, S., Michelena, J., Teloni, F., Imhof, R. \& Altmeyer M.Replication-Coupled Dilution of H4K20me2 Guides 53BP1 to Pre-replicative Chromatin. Cell Rep. 19, 1819-1831 (2017).

49. Sears, C. R., Cooney, S. A., Chin-Sinex, H., Mendonca, M. S. \& Turchi, J. J. DNA damage response (DDR) pathway engagement in cisplatin radiosensitization of non-small cell lung cancer. DNA Repair (Amst). 40, 35-46 (2016).

50. Feringa, F. M. et al. Persistent repair intermediates induce senescence. Nat. Commun. 9, (2018).

51. Leland, B. A., Chen, A. C., Zhao, A. Y., Wharton, R. C. \& King, M. C. Rev7 and 53BP1/CRB2 prevent RecQ helicase-dependent hyper-resection of DNA double-strand breaks. Elife 7, 1-14 (2018).

52. Fradet-Turcotte, A., Canny, M. D. \& Escribano-díaz, C. 53BP1 is a reader of the DNA damageinduced H2A Lys15 ubiquitin mark. 499, 50-54 (2014).

53. Botuyan, M. V. et al. Structural Basis for the Methylation State-Specific Recognition of Histone H4K20 by 53BP1 and Crb2 in DNA Repair. Cell 127, 1361-1373 (2006).

54. Tuzon, C. T. et al. Concerted Activities of Distinct H4K20 Methyltransferases at DNA DoubleStrand Breaks Regulate 53BP1 Nucleation and NHEJ-Directed Repair. Cell Rep. 8, 430-438 (2014).

55. Ernst, J. \& Kellis, M. ChromHMM: automating chromatin-state discovery and characterization. Nat. Methods 9, 215-216 (2012). 
56. Klemm, S. L., Shipony, Z. \& Greenleaf, W. J. Chromatin accessibility and the regulatory epigenome. Nat. Rev. Genet. 20, 29-35 (2019).

57. Calo, E. \& Wysocka, J. Modification of Enhancer Chromatin: What, How, and Why? Mol. Cell 49, 825-837 (2013).

58. Thakore, P. I. et al. Highly specific epigenome editing by CRISPR-Cas9 repressors for silencing of distal regulatory elements. Nat. Methods 12, 1143-1149 (2015).

59. Gorisch, S. M. Histone acetylation increases chromatin accessibility. J. Cell Sci. (2005). doi:10.1242/jcs.02689

60. Floyd, S. R. et al. The bromodomain protein Brd4 insulates chromatin from DNA damage signalling. Nature 498, 246-250 (2013).

61. Sternberg, S. H., Redding, S., Jinek, M., Greene, E. C. \& Doudna, J. A. DNA interrogation by the CRISPR RNA-guided endonuclease Cas9. Nature 507, 62-67 (2014).

62. Daugaard, M. et al. LEDGF (p75) promotes DNA-end resection and homologous recombination. Nat. Struct. Mol. Biol. 19, 803-810 (2012).

63. Broderick, R. et al. EXD2 promotes homologous recombination by facilitating DNA end resection. Nat. Cell Biol. 18, 271-280 (2016).

64. Dong, S. et al. The human SRCAP chromatin remodeling complex promotes DNA-end resection. Curr. Biol. 24, 2097-2110 (2014).

65. Keeney, S., Lange, J. \& Mohibullah, N. Self-Organization of Meiotic Recombination Initiation: General Principles and Molecular Pathways. Annu. Rev. Genet. 48, 187-214 (2014).

66. Stanlie, A., Aida, M., Muramatsu, M., Honjo, T. \& Begum, N. A. Histone3 lysine4 trimethylation regulated by the facilitates chromatin transcription complex is critical for DNA cleavage in class switch recombination. Proc. Natl. Acad. Sci. 107, 22190-22195 (2010).

67. Stratton, M. R., Campbell, P. J. \& Futreal, P. A. The cancer genome. Nature 458, 719-724 (2009).

68. Greenman, C. et al. Patterns of somatic mutation in human cancer genomes. Nature 446, 153158 (2007).

69. Imielinski, M., Guo, G. \& Meyerson, M. Insertions and Deletions Target Lineage-Defining Genes in Human Cancers. Cell 168, 460-472.e14 (2017). 
70. Chailleux, C. et al. Quantifying DNA double-strand breaks induced by site-specific endonucleases in living cells by ligation-mediated purification. Nat. Protoc. 9, 517-28 (2014).

71. Stork, C. T. et al. Co-transcriptional R-loops are the main cause of estrogen-induced DNA damage. Elife 5, 1-21 (2016).

72. Chen, L. et al. R-ChIP Using Inactive RNase H Reveals Dynamic Coupling of R-loops with Transcriptional Pausing at Gene Promoters. Mol. Cell 68, 745 (2017).

73. Doench, J. G. et al. Optimized sgRNA design to maximize activity and minimize off-target effects of CRISPR-Cas9. Nat. Biotechnol. 34, 1-12 (2016).

74. Haeussler, M. et al. Evaluation of off-target and on-target scoring algorithms and integration into the guide RNA selection tool CRISPOR. Genome Biol. 17, 1-12 (2016),

75. Jacobi, A. M. et al. Simplified CRISPR tools for efficient genome editing and streamlined protocols for their delivery into mammalian cells and mouse zygotes. Methods 121-122, 16-28 (2017).

76. Feringa, F. M. et al. Hypersensitivity to DNA damage in antephase as a safeguard for genome stability. Nat. Commun. 7, 12618 (2016).

77. Lukinavičius, G. et al. SiR-Hoechst is a far-red DNA stain for live-cell nanoscopy. Nat. Commun. 6, $1-7$ (2015).

78. Stelloo, S. et al. Endogenous androgen receptor proteomic profiling reveals genomic subcomplex involved in prostate tumorigenesis. Oncogene 37, 313-322 (2018). 


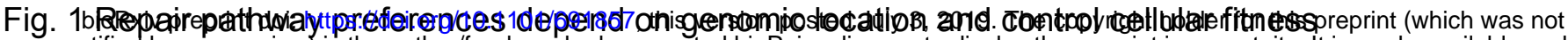
certified by peer review) is the author/funder, who has granted bioRxiv a license to display the preprint in perpetuity. It is made available unde

A

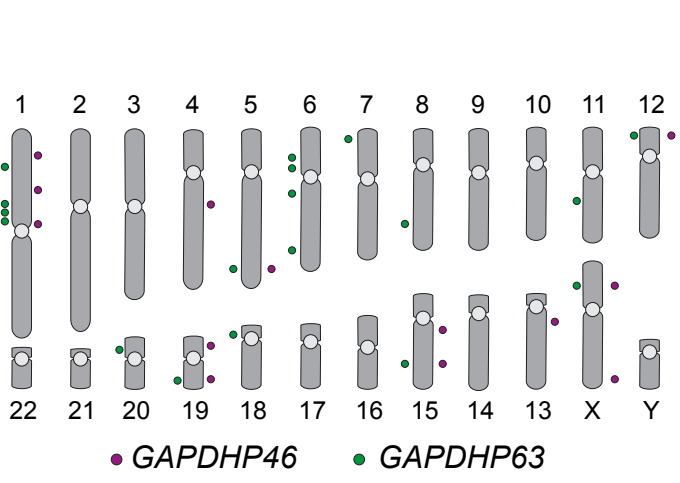

${ }^{\mathrm{aCC}} \mathrm{B}$

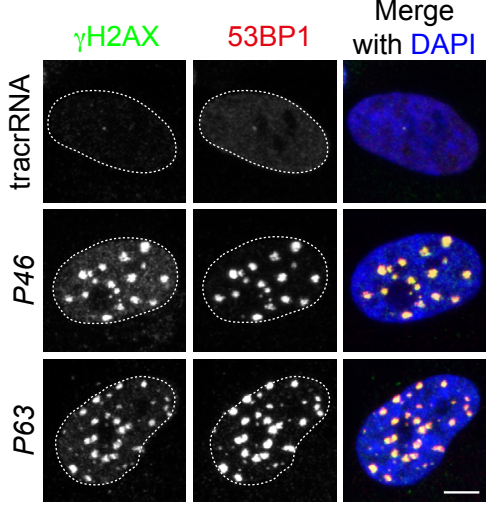

C

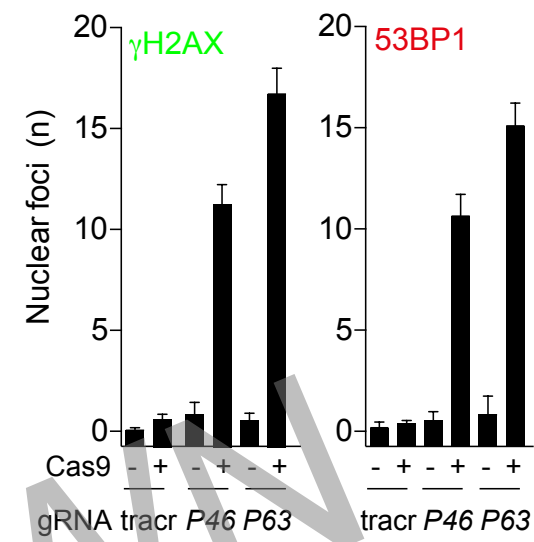

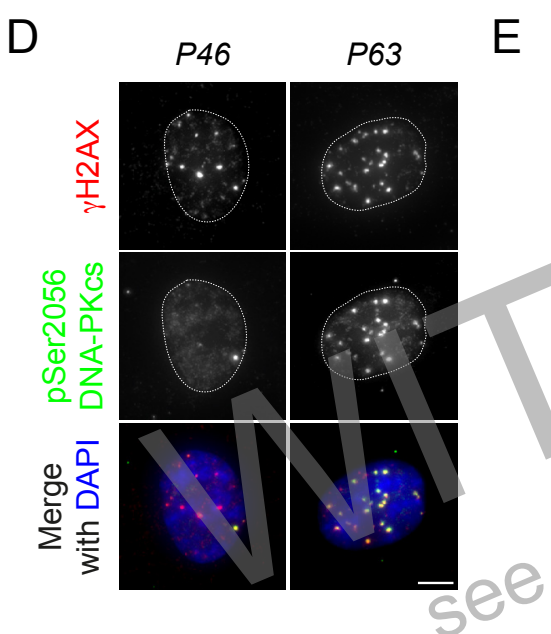

$\mathrm{H}$

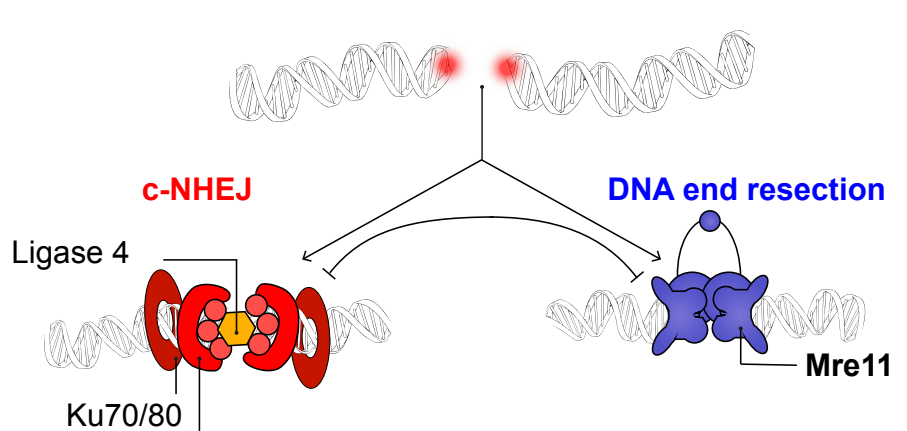

DNA-PKcs

$J$

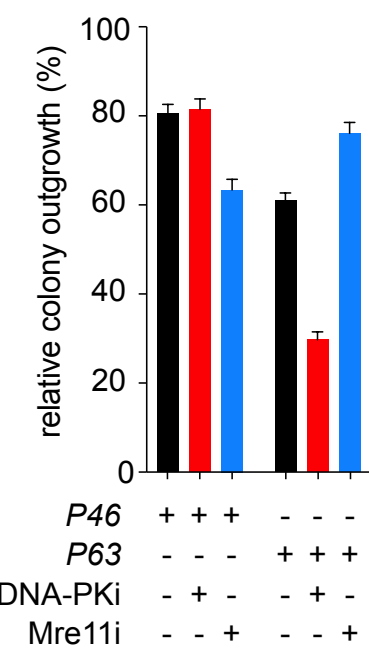

$\mathrm{K}$

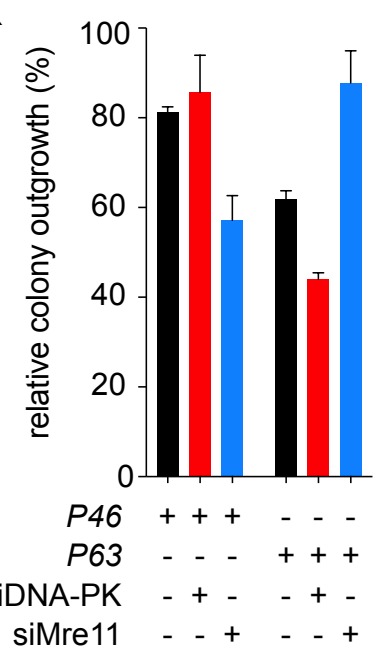

F
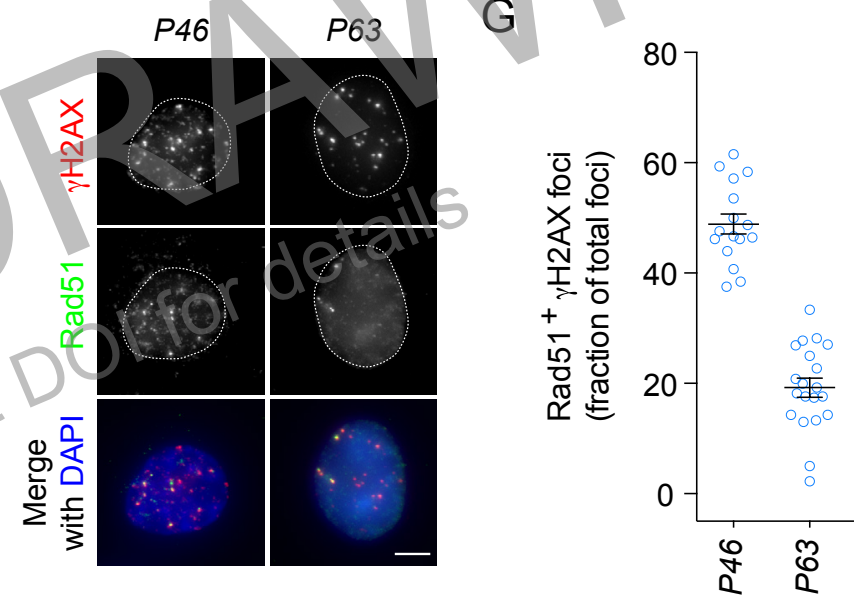

I

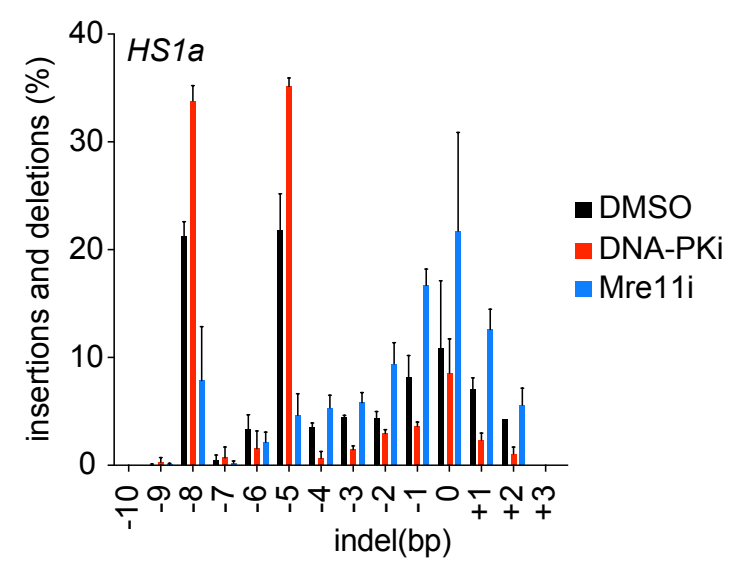

L

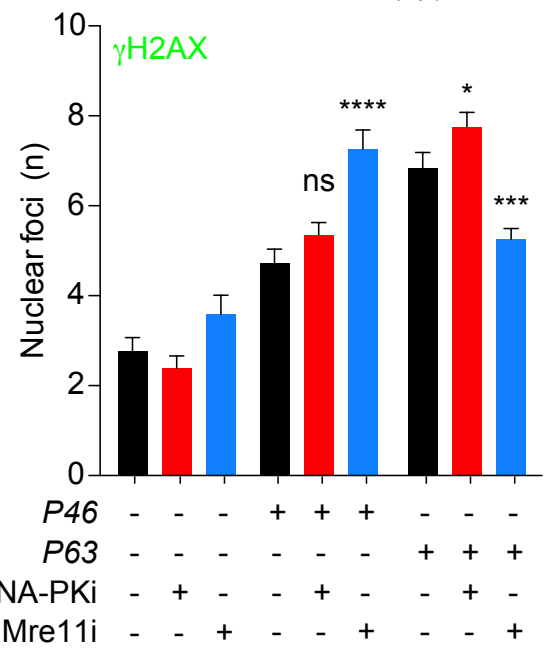




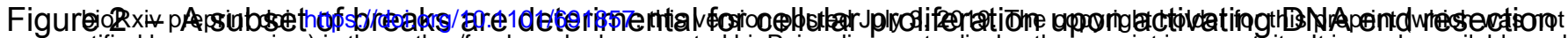
certified by peer review) is the author/funder, who has granted bioRxiv a license to display the preprint in perpetuity. It is made available under

A

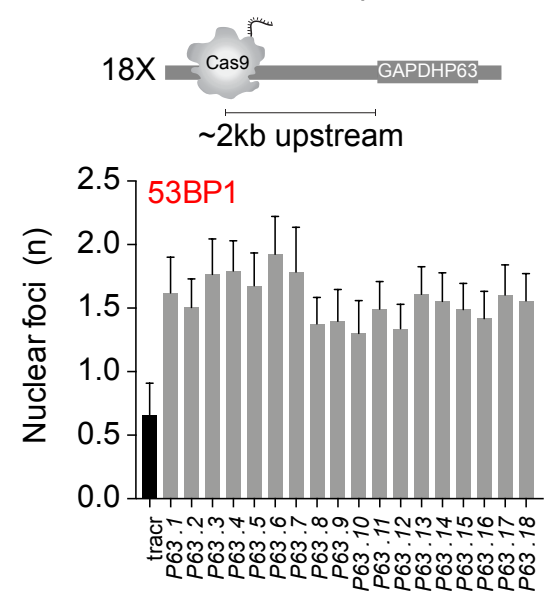

B

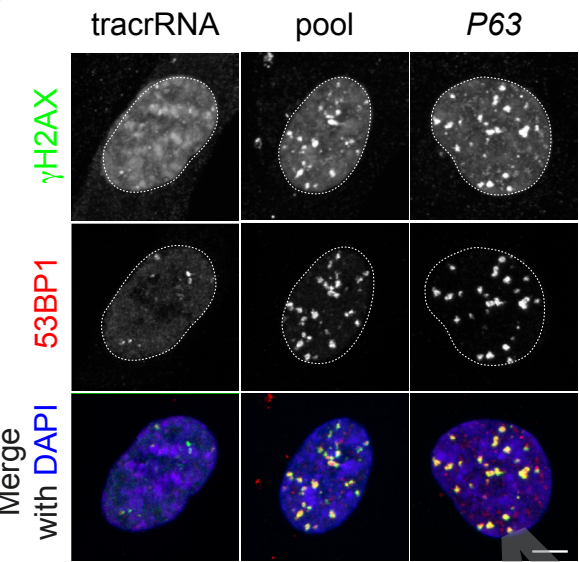

$\mathrm{F}$
C

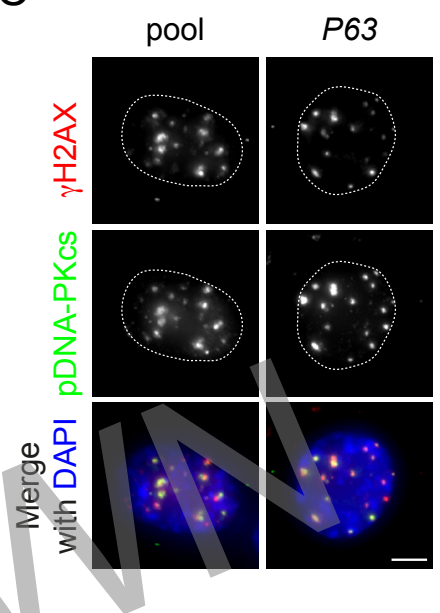

$\mathrm{D}$

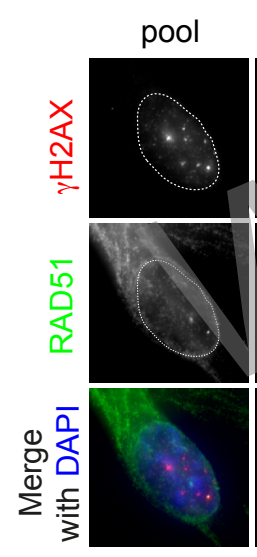

$\mathrm{H}$

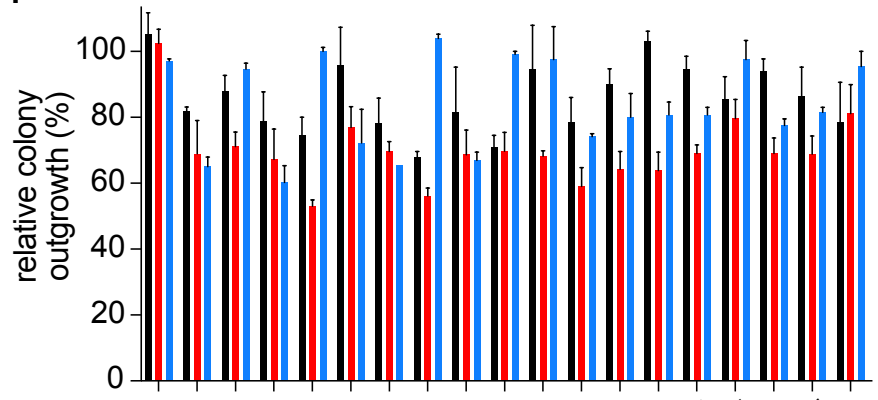

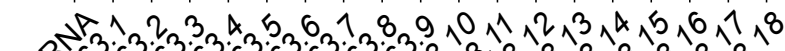

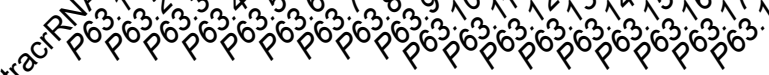

J

- Mre11i
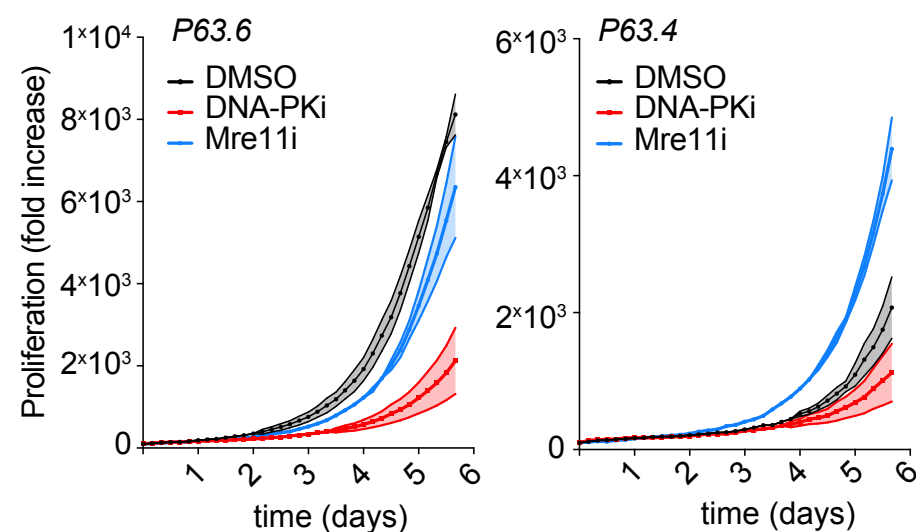
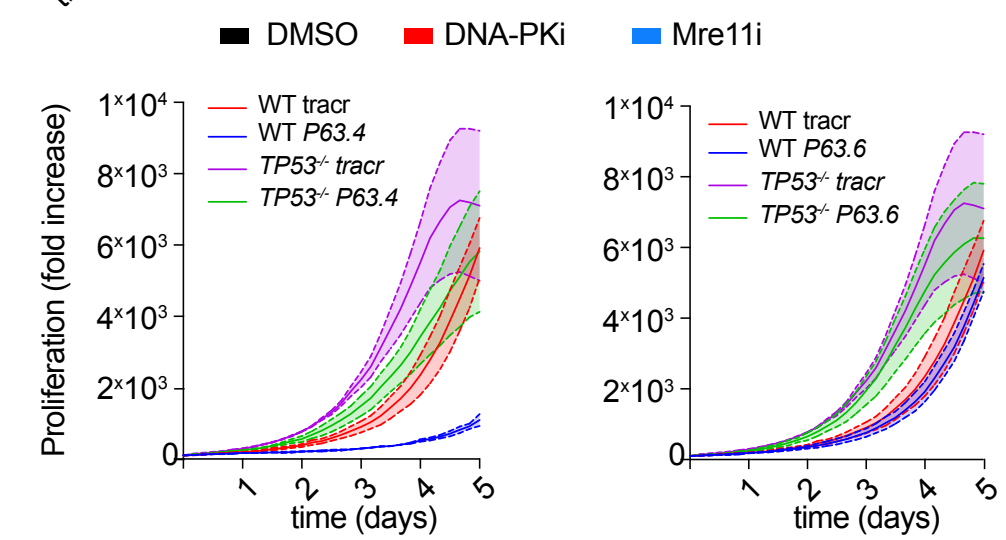

G
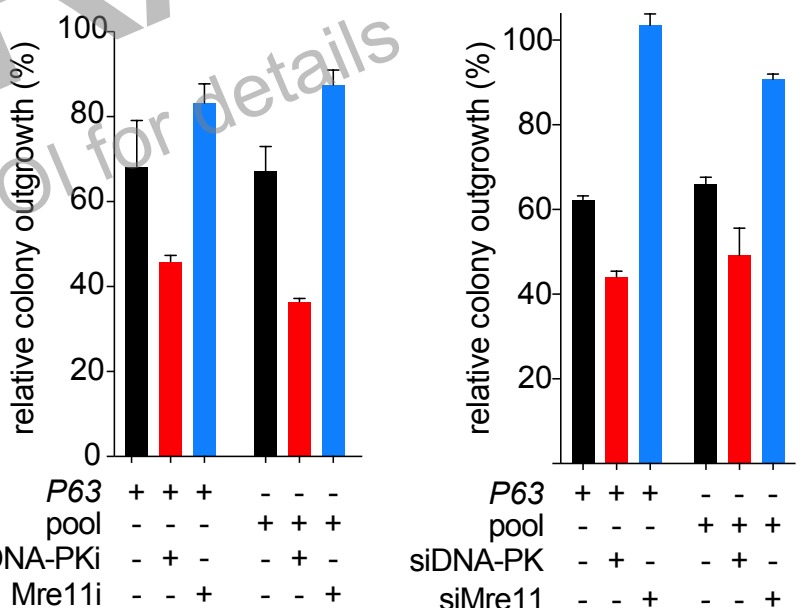


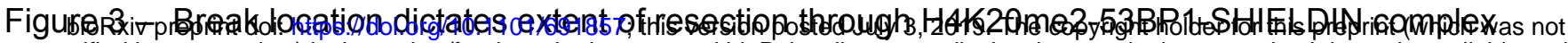
certified by peer review) is the author/funder, who has granted bioRxiv a license to display the preprint in perpetuity. It is made available under

A

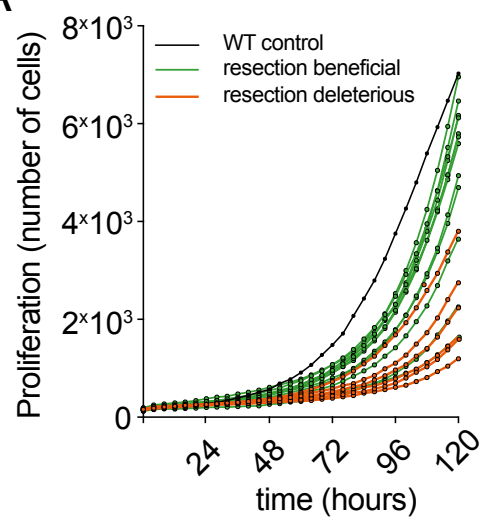

D

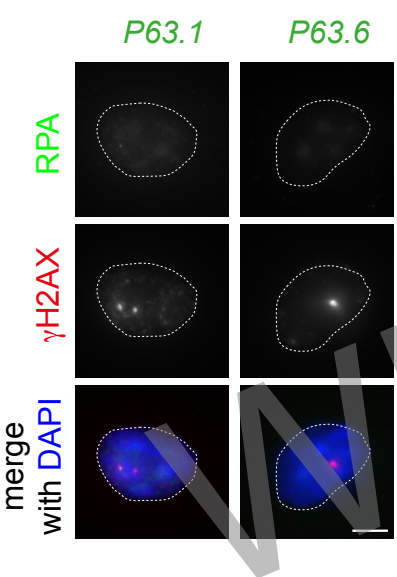

E
B

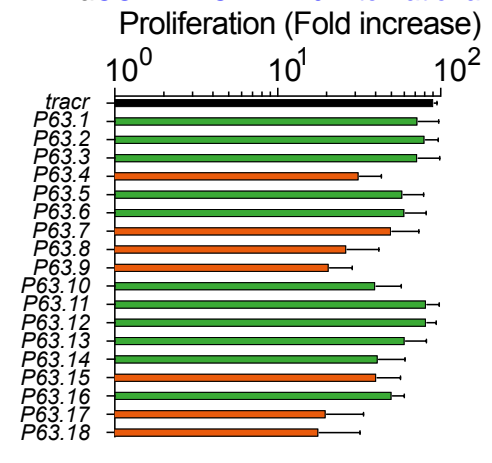

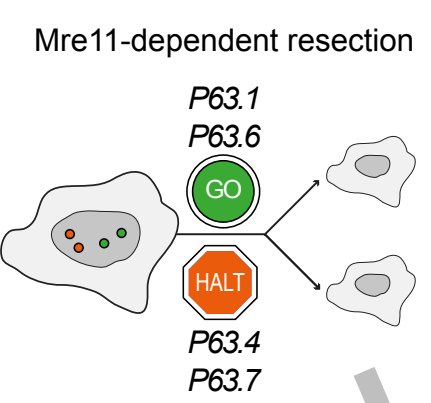

G

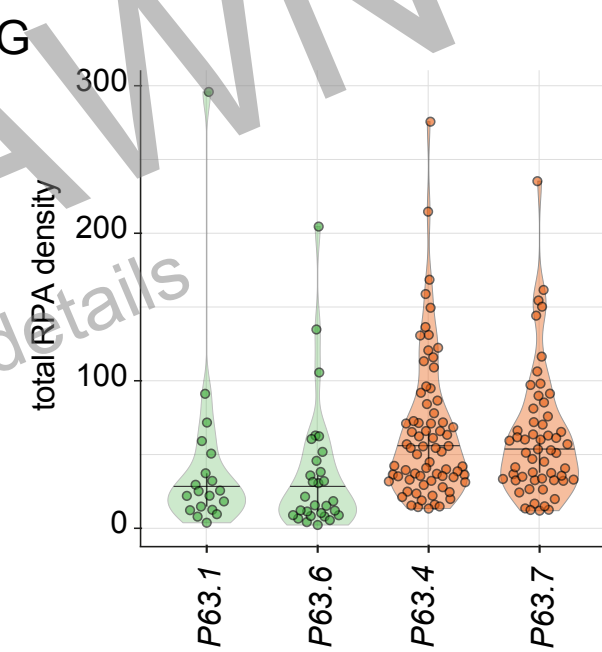

$J$
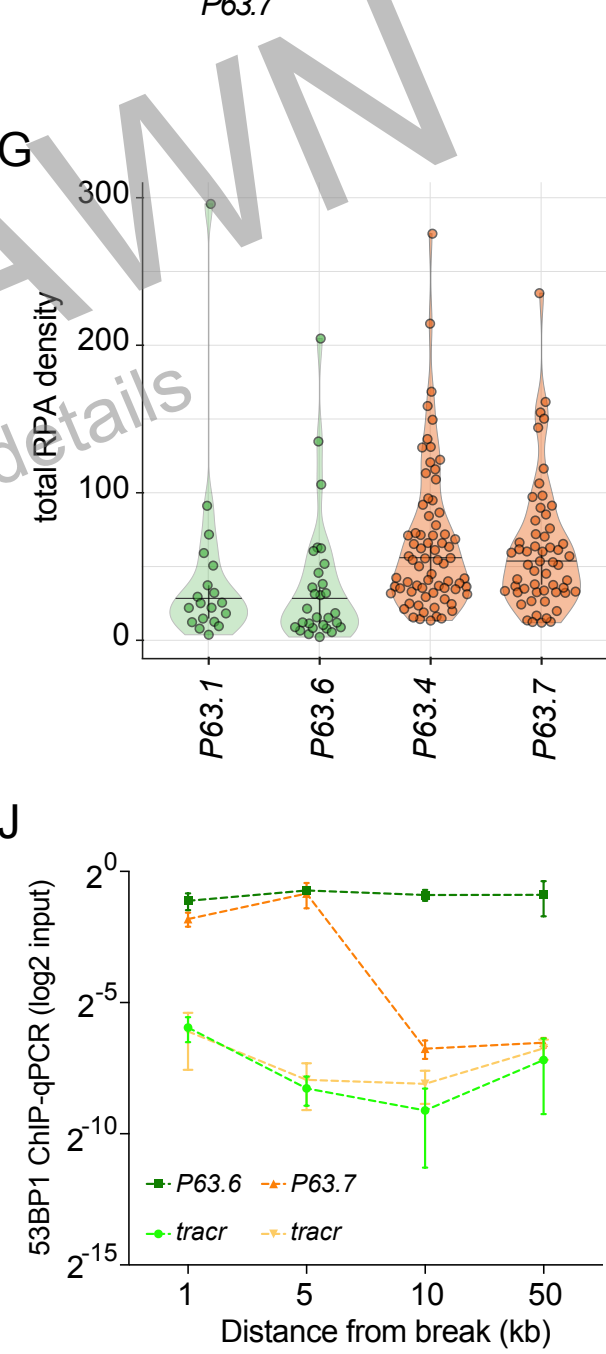

$\mathrm{K}$

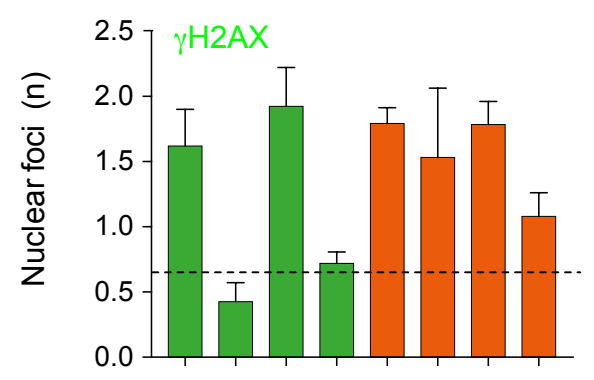

induction $(8 \mathrm{hr})+-+-++-$

repair (24hr) $\frac{-+}{P 63.1} \frac{-+}{P 63.6} \frac{-+}{P 63.4} \frac{-\quad+}{P 63.7}$
I

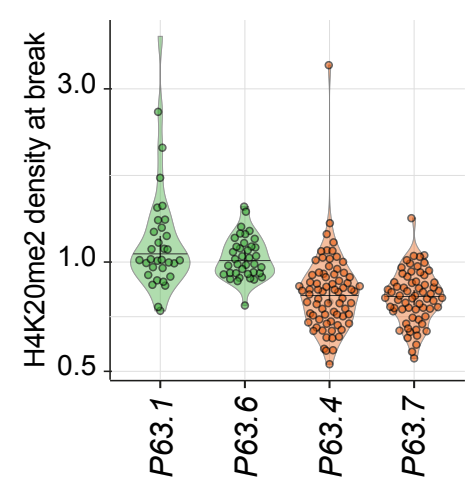

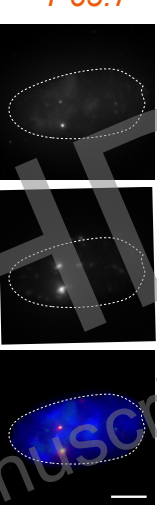

ஜ্

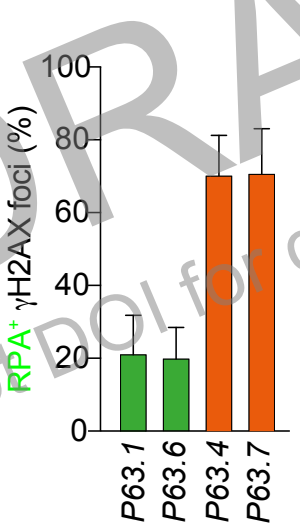

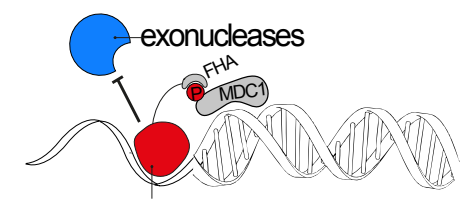

OB-fold domain Shieldin-2
$\mathrm{L}$

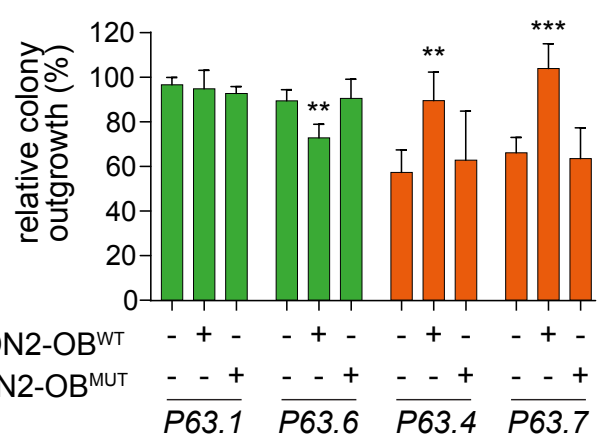




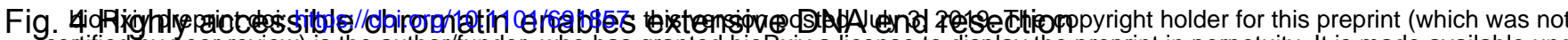
certified by peer review) is the author/funder, who has granted bioRxiv a license to display the preprint in perpetuity. It is made available under

A

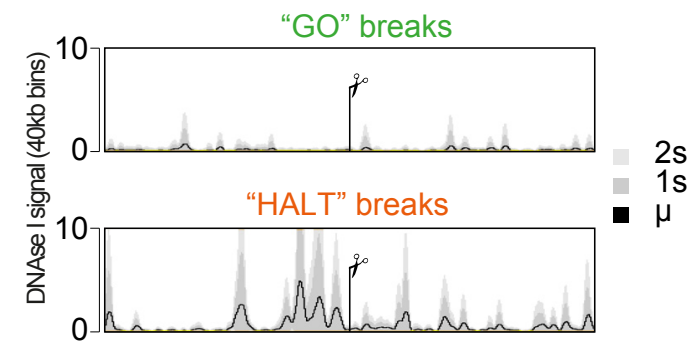

C

P63.7

spCas9

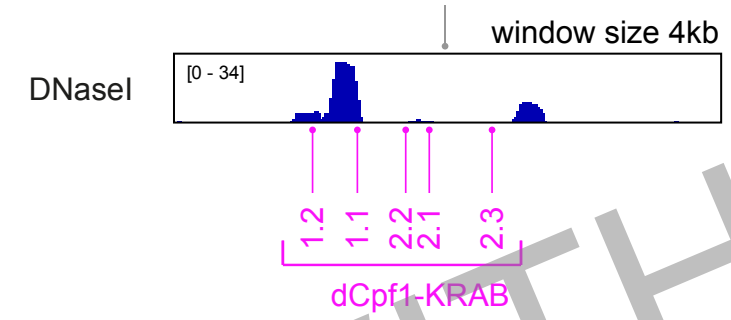

$E$

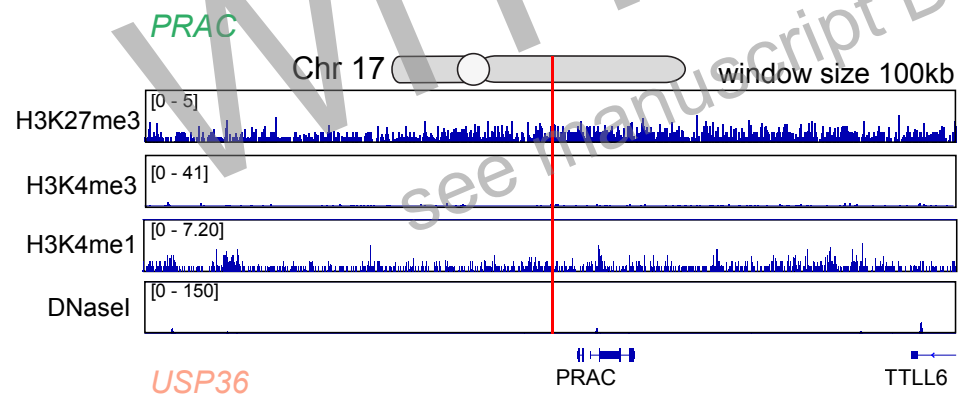

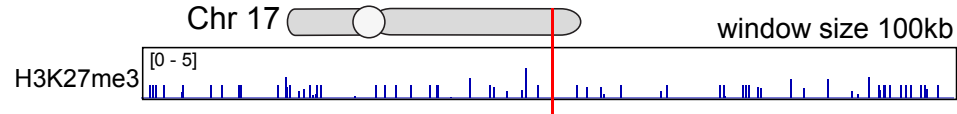

H3K4me3 \begin{tabular}{|l|l|l|}
{$[0-41]$} & L
\end{tabular}

H3K4me1 1

DNasel CYTH1 W..........

-11-11-H+ III, IIII,

G

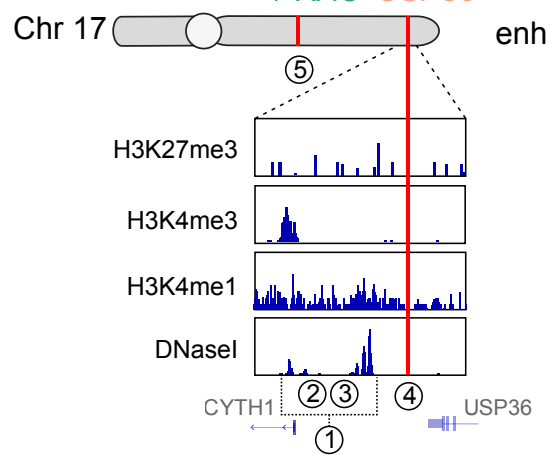

tot. window size $22.8 \mathrm{~kb}$

$\mathrm{H}$

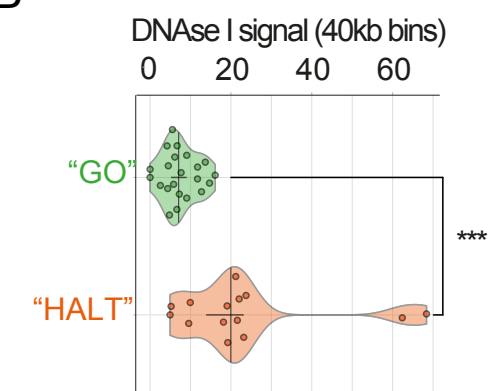

$\mathrm{D}$

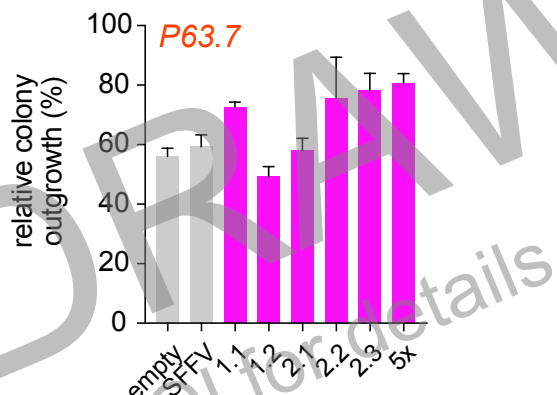

F
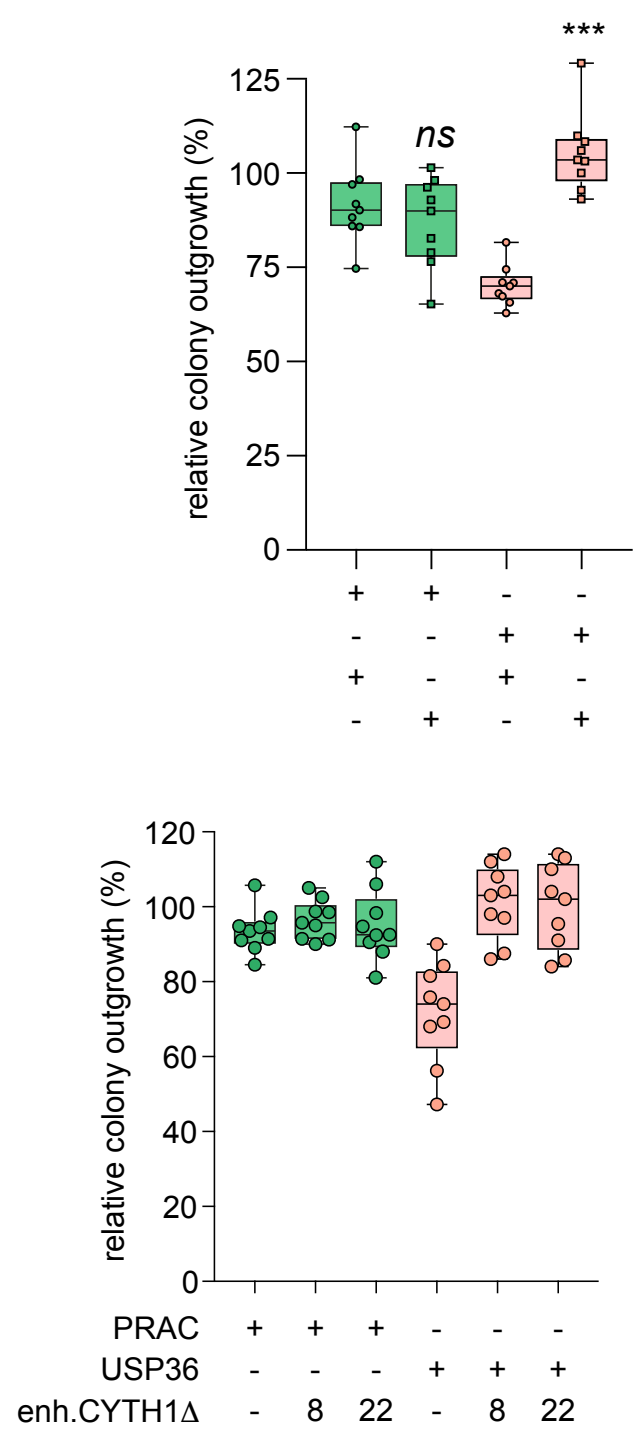


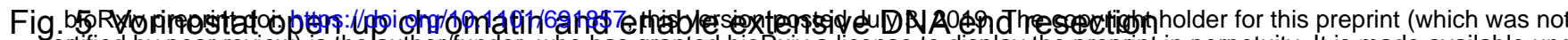
certified by peer review) is the author/funder, who has granted bioRxiv a license to display the preprint in perpetuity. It is made available under

A

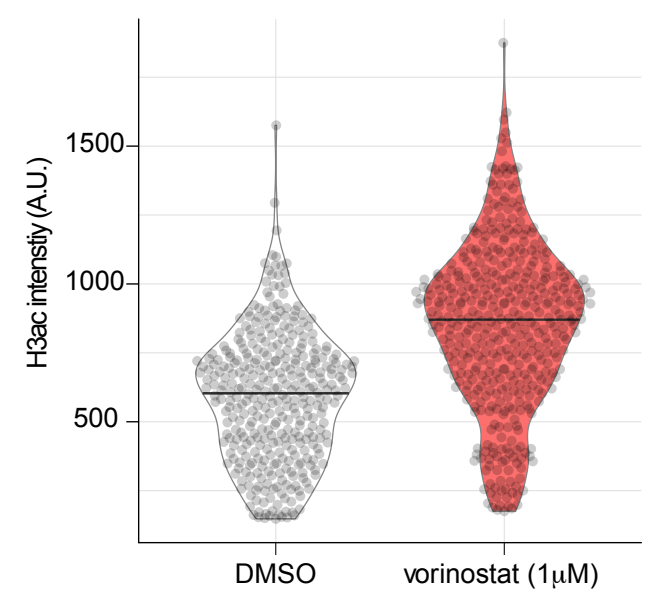

C

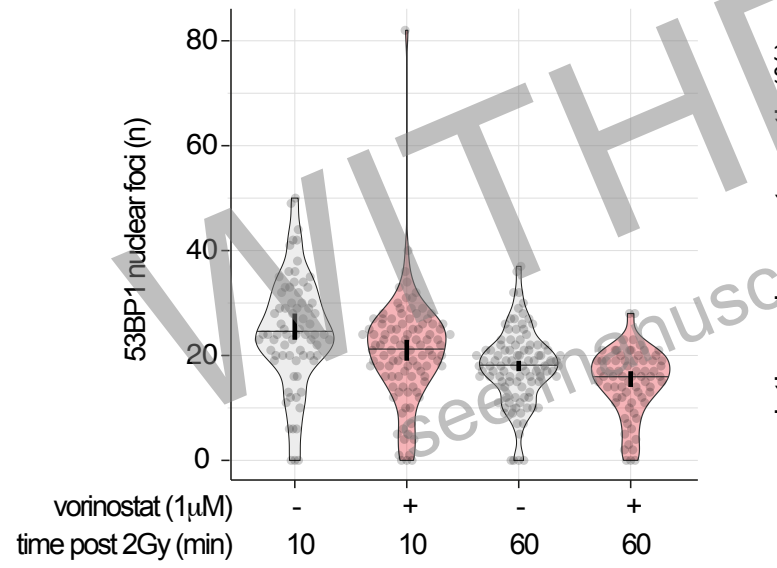

E

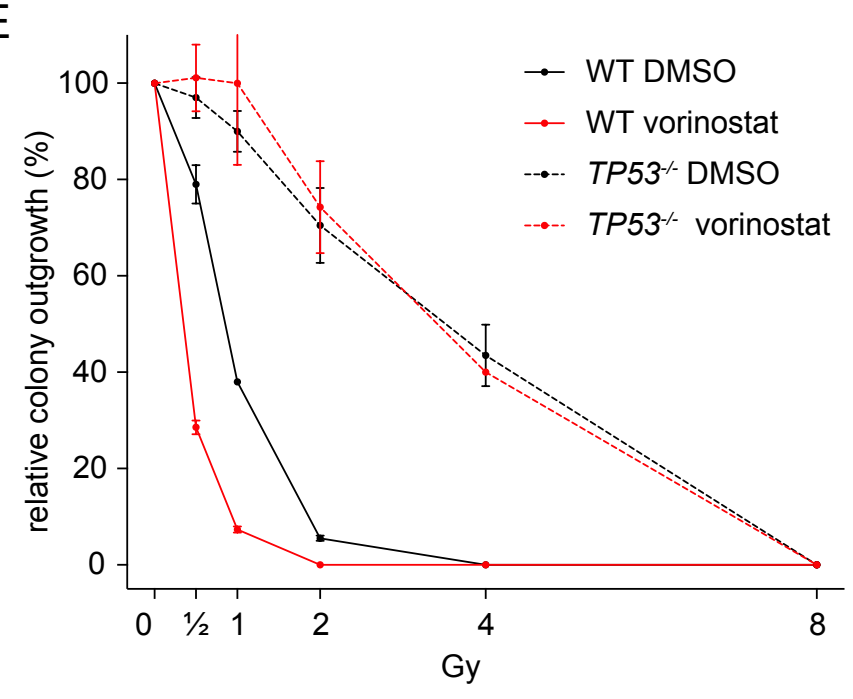

B

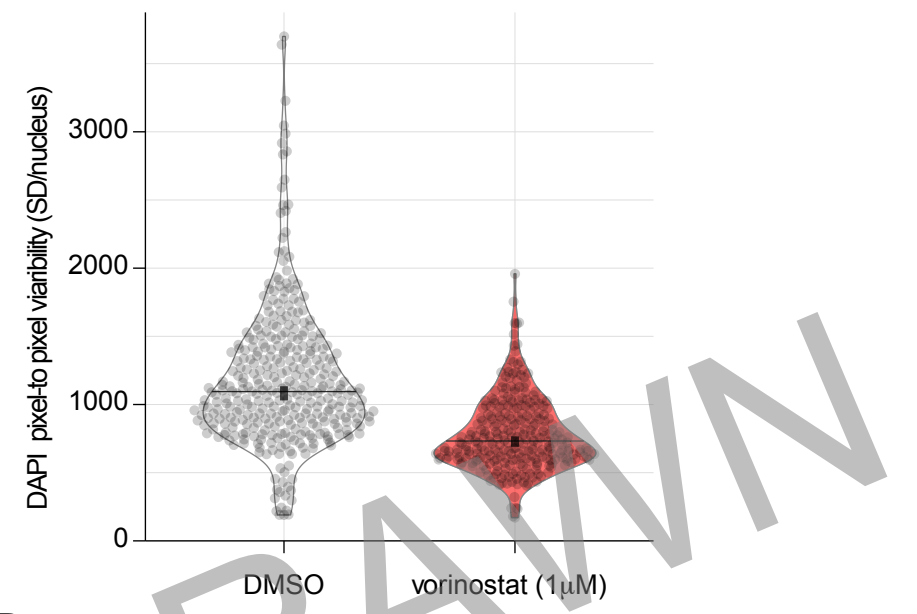

D

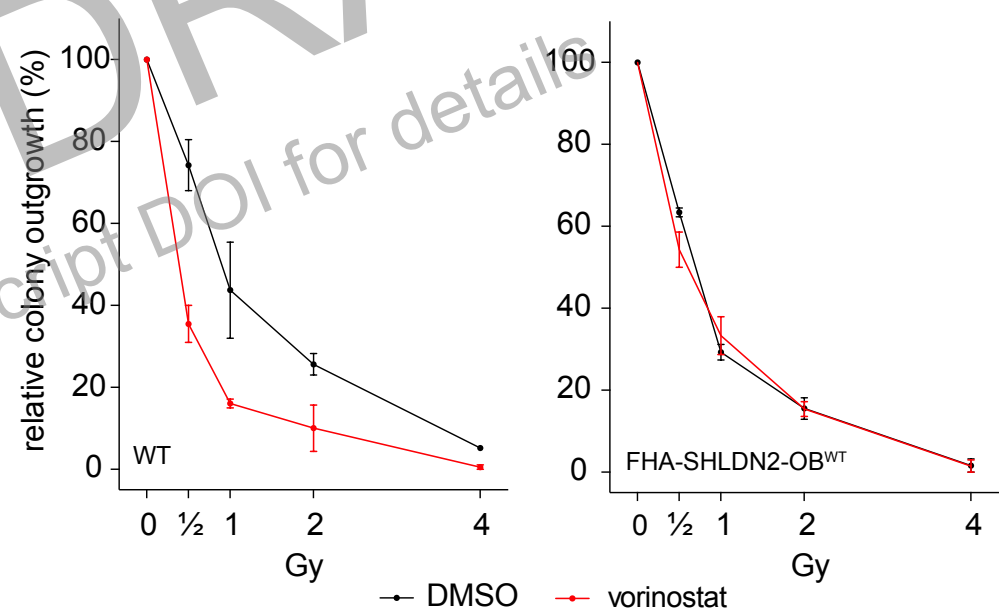

$\mathrm{F}$

4 hours post $2 \mathrm{~Gy}$ 
Fig. 6 - Deleterious DNA end resection is permitted in highly accessible chromatin due to the lack of

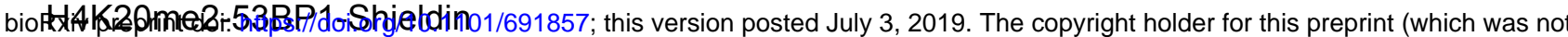
certified by peer review) is the author/funder, who has granted bioRxiv a license to display the preprint in perpetuity. It is made available under aCC-BY-NC-ND 4.0 International license.

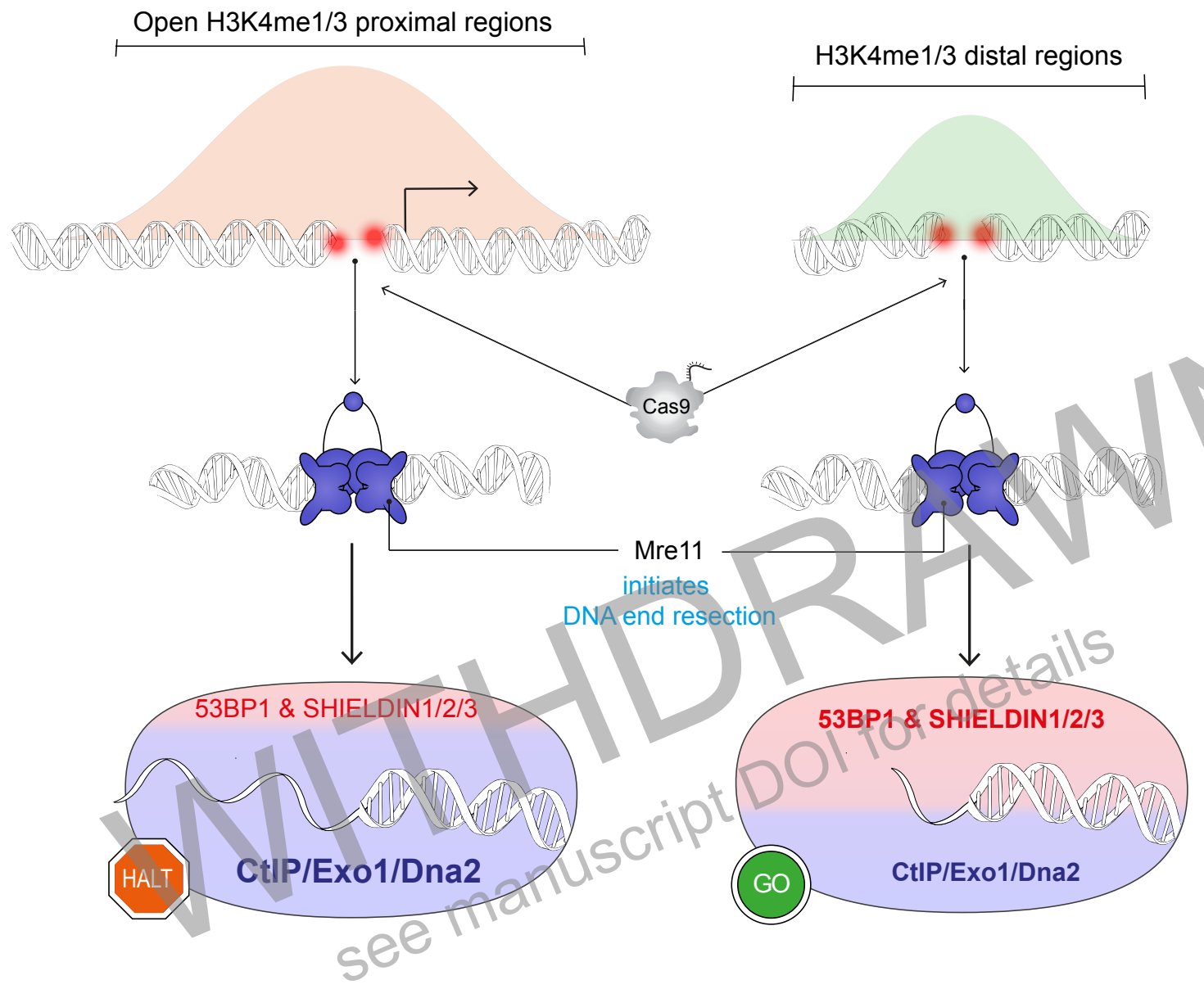


Suppl. Fig. 1 - Toxic repair mediated by DNA end resection on a subset of breaks

bioRxiv preprint doi: https://doi.org/10.1101/691857; this version posted July 3, 2019. The copyright holder for this preprint (which was not

A certified by peer review) is the author/funder, who has Banted bjoRxiv a license to display the preprint in perpetuity. It is made available under

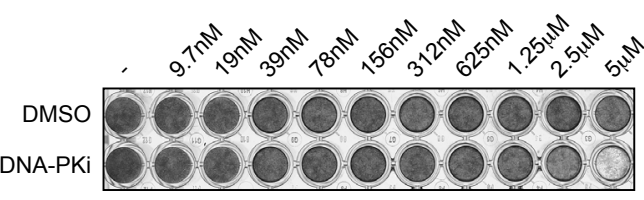

C

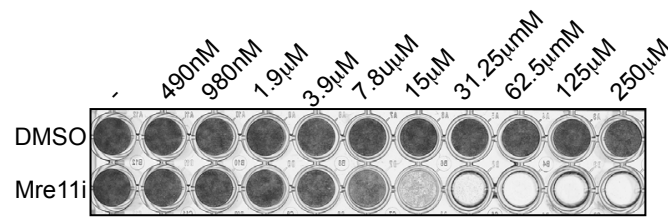

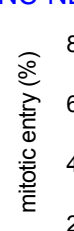

$\mathrm{D}$

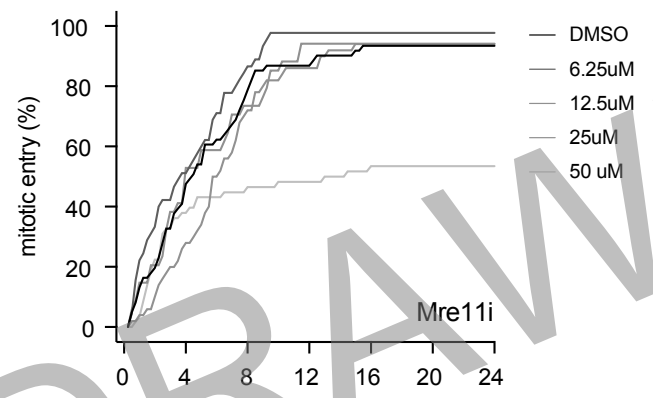

$-2.5 \mathrm{uM}$

$-5 \mathrm{uM}$
$-10 \mathrm{uM}$

NA-PKi
$E$

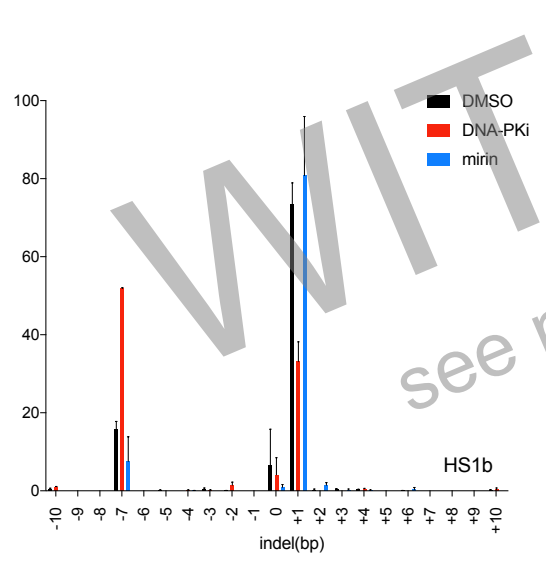

$\mathrm{H}$

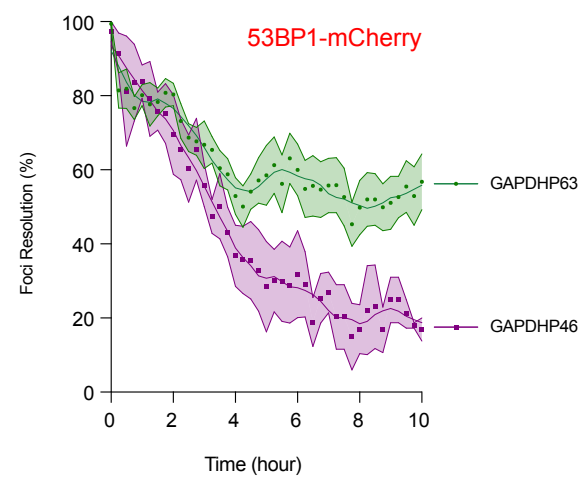

\section{H}

$\mathrm{F}$

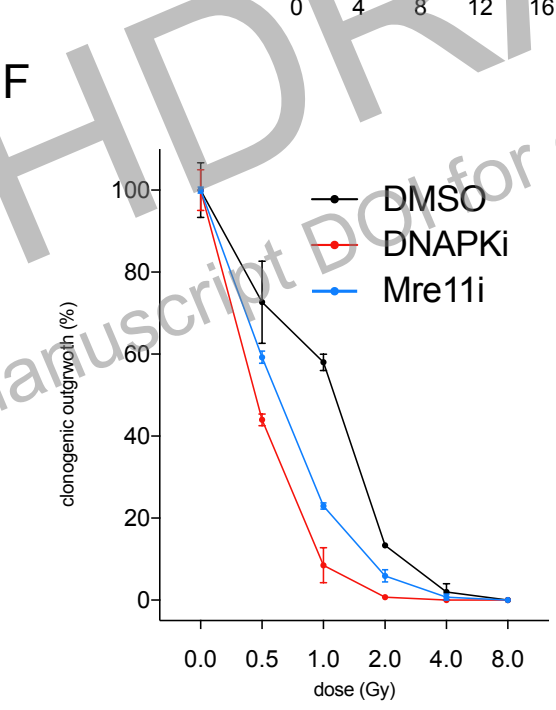

- DMSO

G

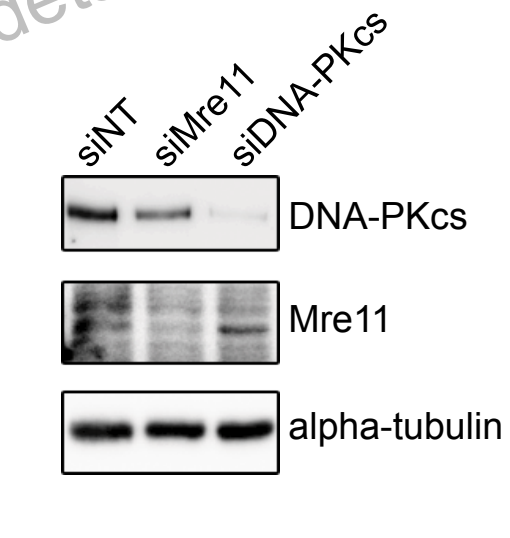

(2)

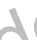

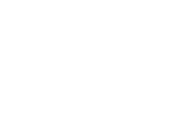


Suppl. Fig. 2 - Single breaks reveal differential repair pathway requirements and proliferative capacities

bioRxiv preprint doi: https://doi.org/10.1101/691857; this version posted July 3, 2019. The copyright holder for this preprint (which was not A certified by peer review) is the author/funder, who has gr Rted bioRxiv a license to display the preprint in perpetuity. It is made available under

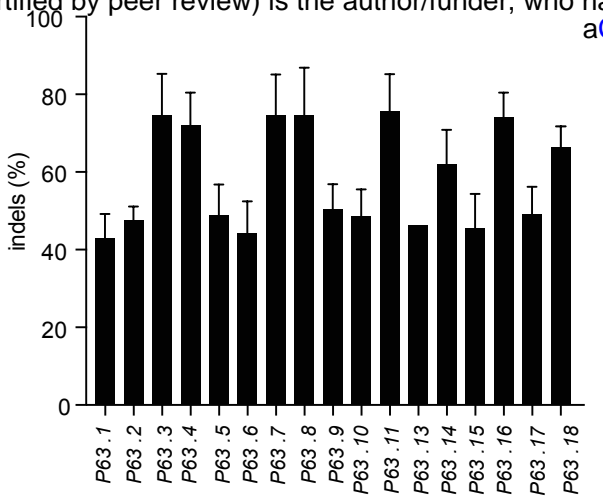
aCC-BY-NC-ND 4.0 International license.

C

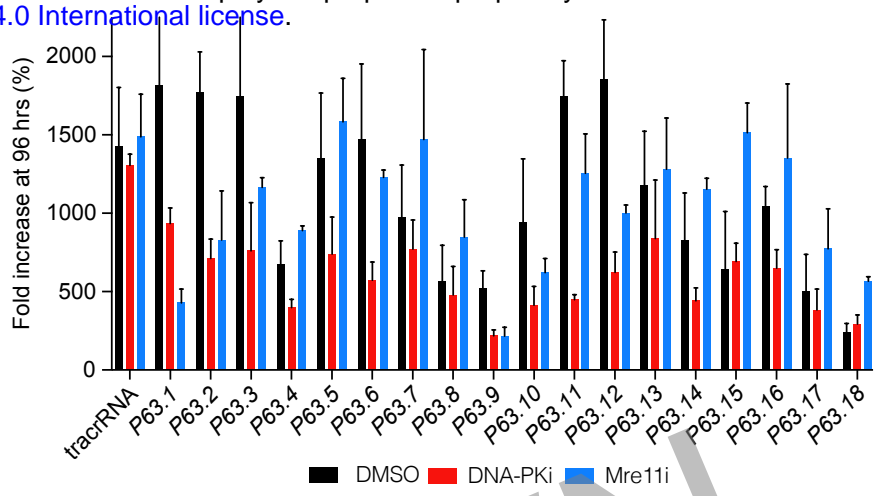

D

$\mathrm{E}$

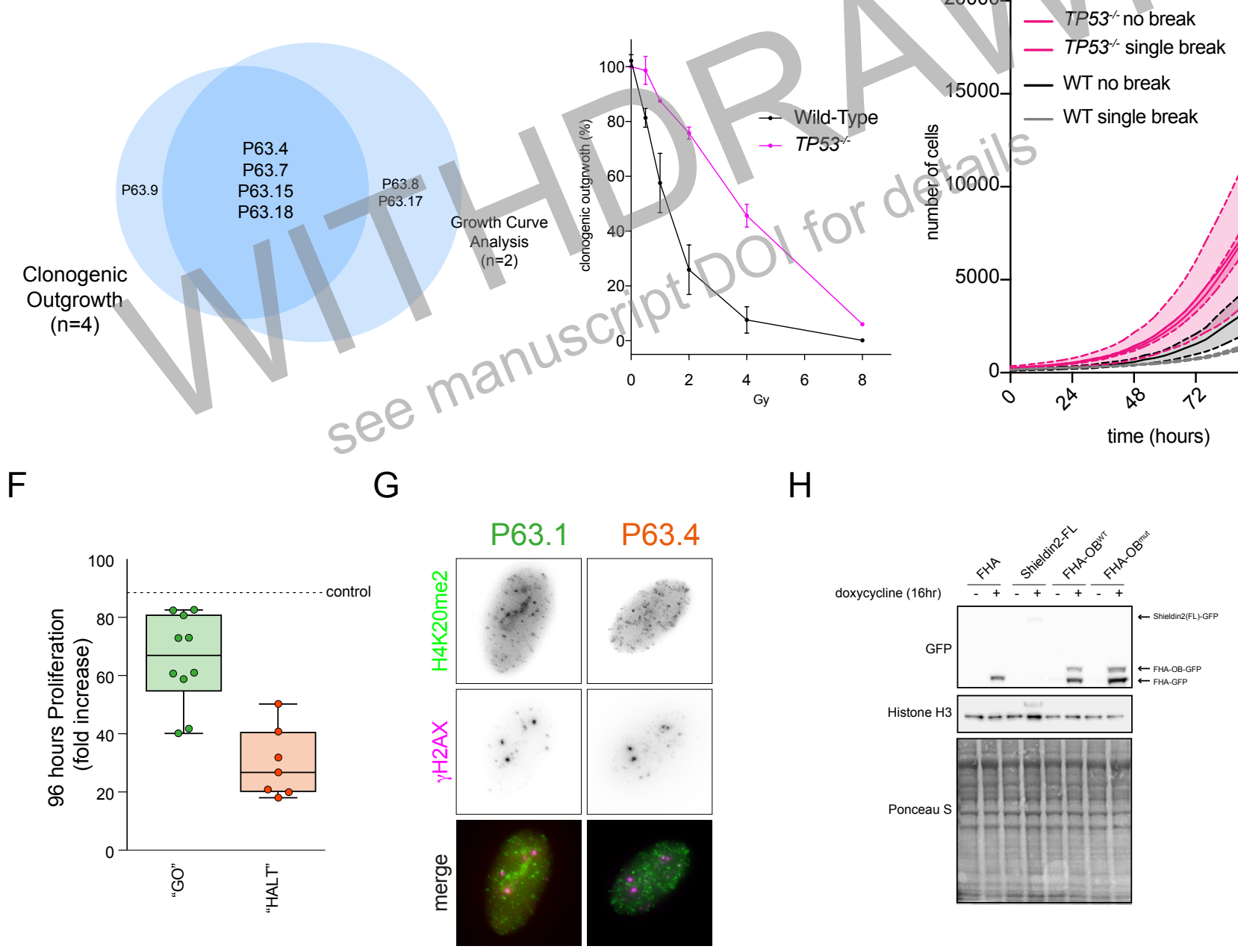


Suppl. Fig. 3 - Epigenome and trasncriptome analysis of RPE-1 hTERT

bioRxiv preprint doi: https://doi.org/10.1101/691857; this version posted July 3, 2019. The copyright holder for this preprint (which was not certified by peer review) is the author/funder, who has granted bioRxiv a license to display the preprint in perpetuity. It is made available under

Genome

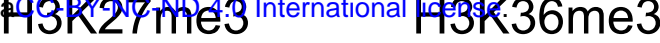
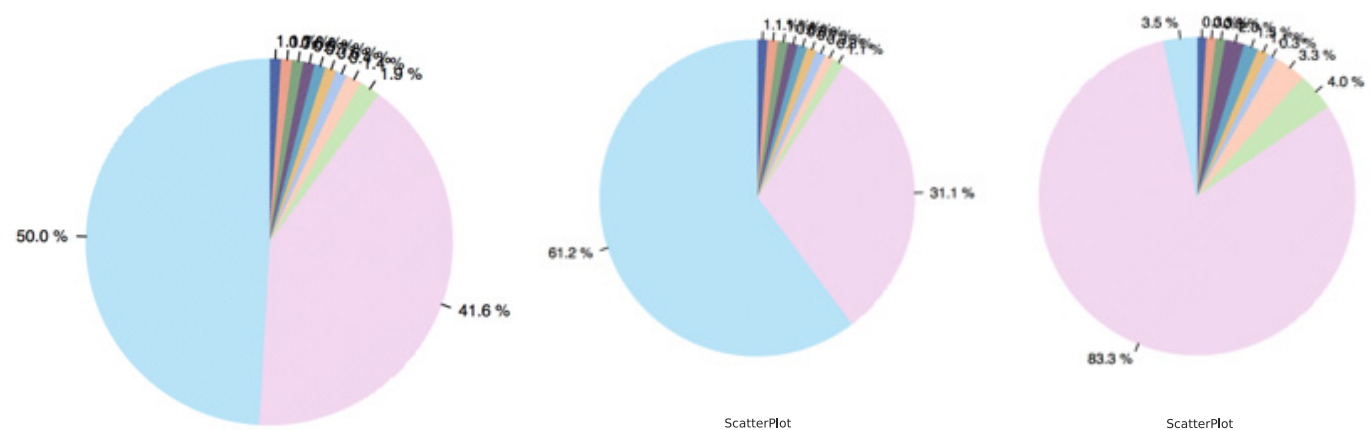

- Promoter (<=1000 bp): $1.1 \%$

- Promoter (1000-2000 bp): $0.7 \%$

- Promoter (2000-3000 bp): $0.6 \%$

- Downstream (<=1000 bp): $0.9 \%$

- Downstream (1000-2000 bp): $0.7 \%$

Downstream (2000-3000 bp): $0.6 \%$

5'UTR: $0.4 \%$

3'UTR: $1.4 \%$

Coding exon: $1.9 \%$

Intron: $41.6 \%$

Distal intergenic: $50.0 \%$

H3K4me1
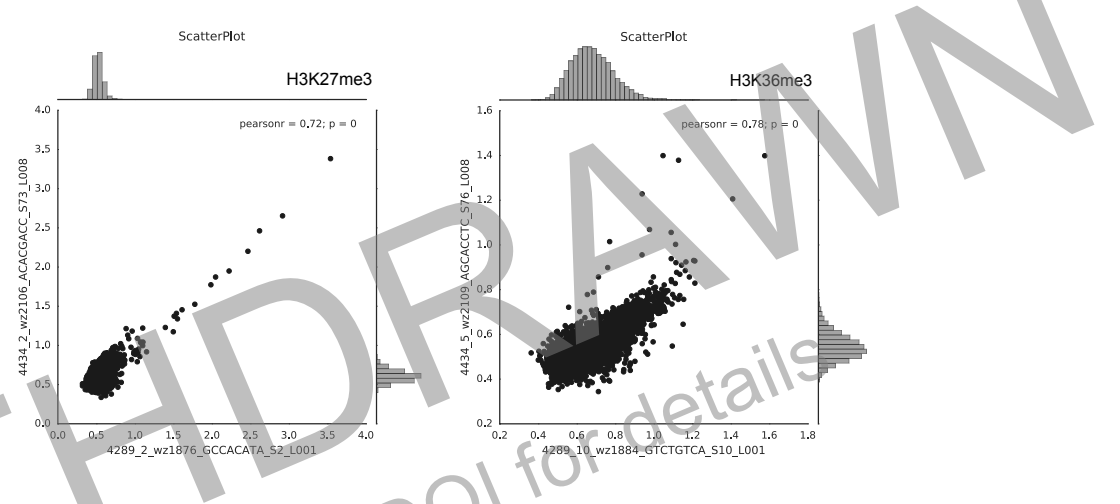

H3K4me3

H3K9me3
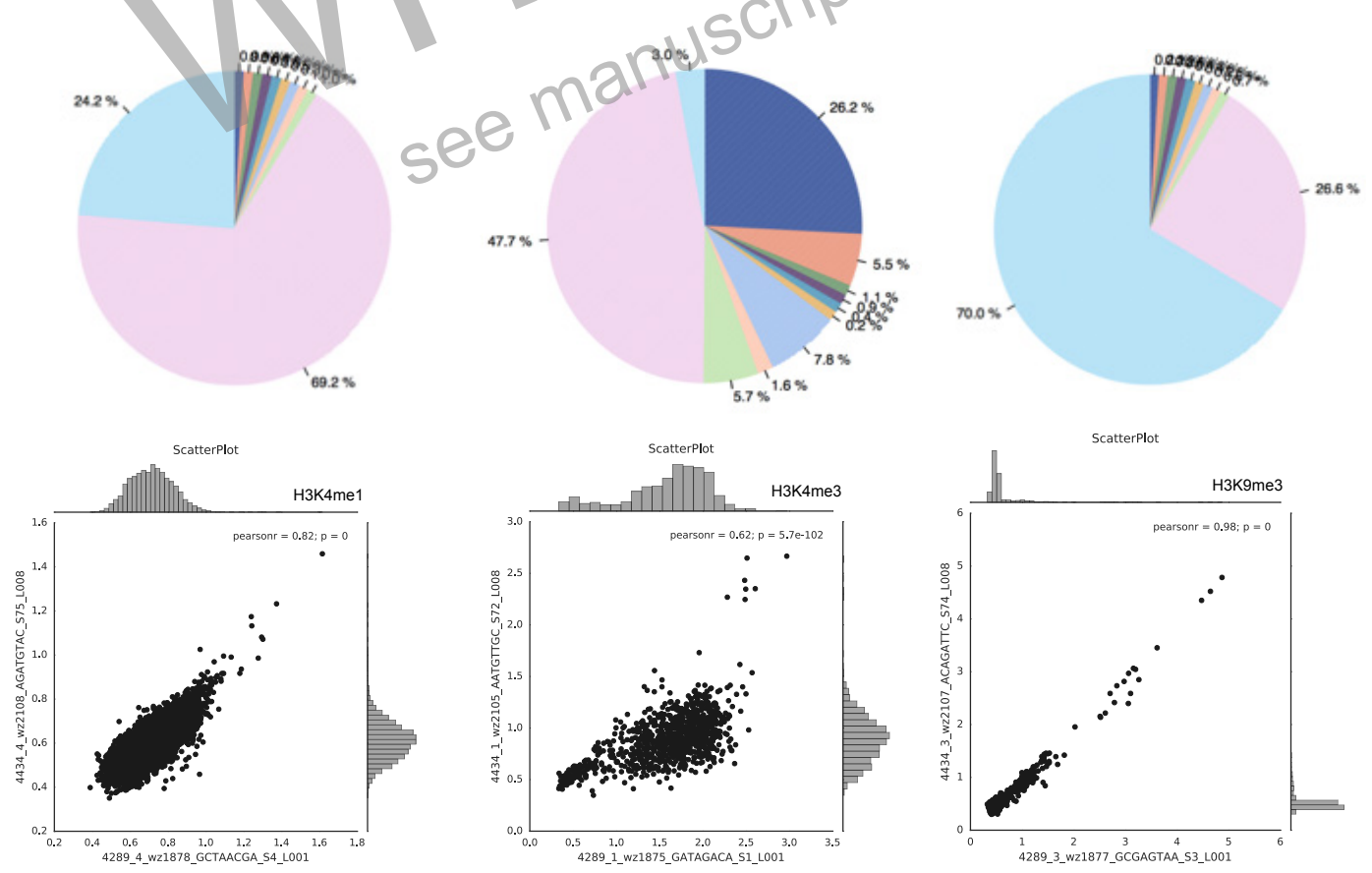
Suppl. Fig. 4 - Open chromatin permits extensive and deleterious DNA end resection

bioRxiv preprint doi: https://doi.org/10.1101/691857; this version posted July 3, 2019. The copyright holder for this preprint (which was not

A

certified by peer review) is the author/funder, who has granted bioRxiv a license to display the preprint in perpetuity. It is made available under

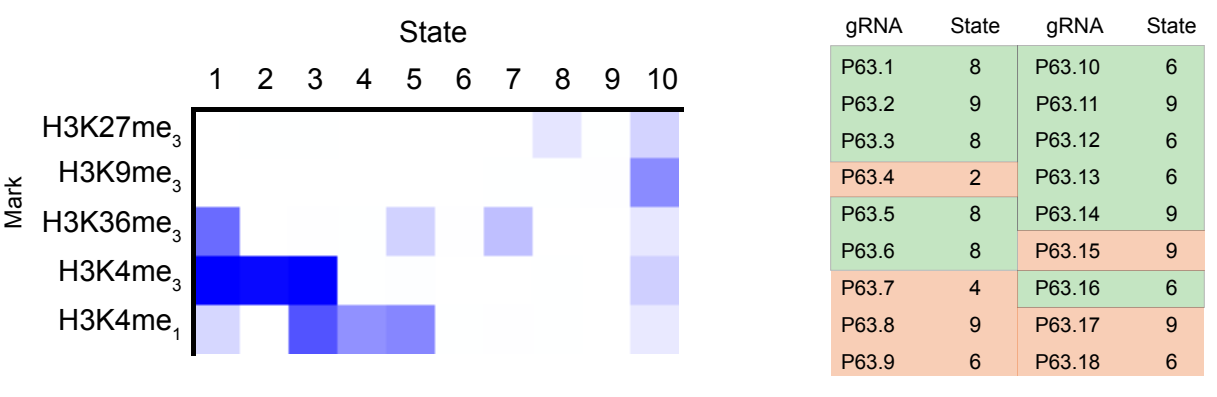
has granted bioRxiv a license to display the preprint in perpetuity. It is made available under
aCCBY-NC-ND 4.0 International license.

$\mathrm{D}$ E

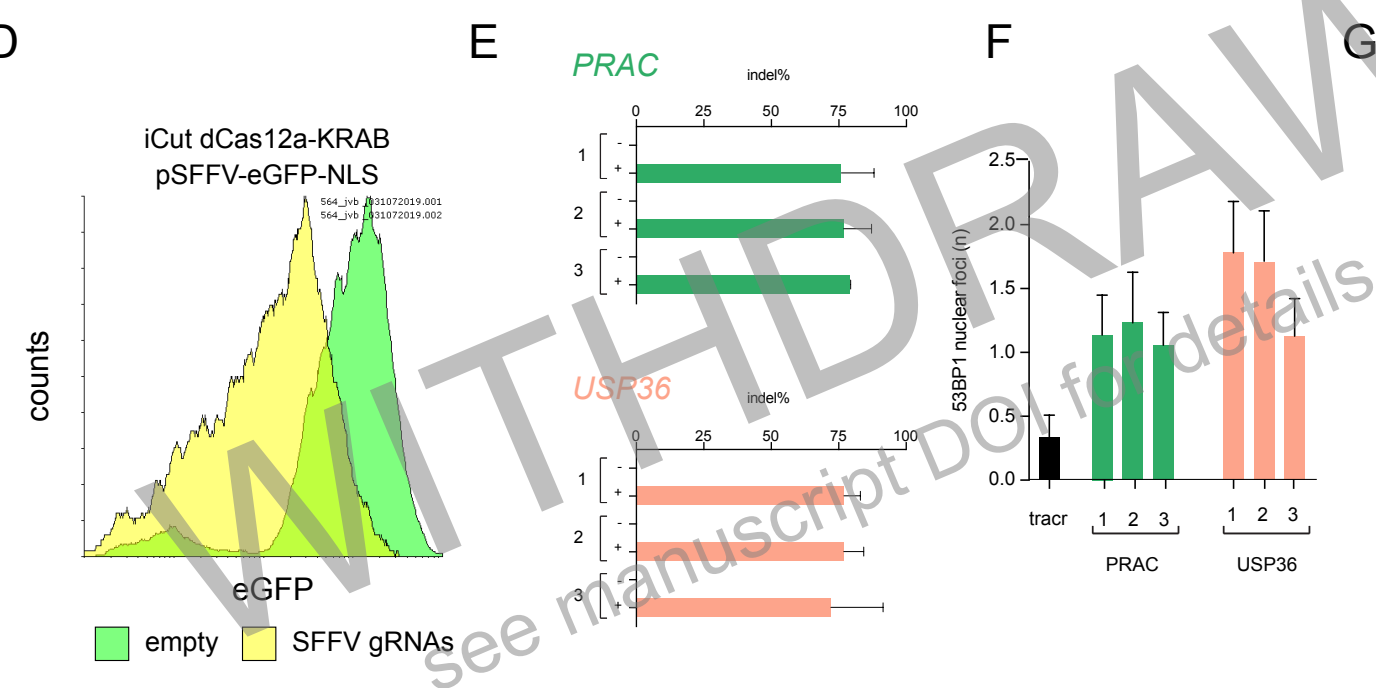

F

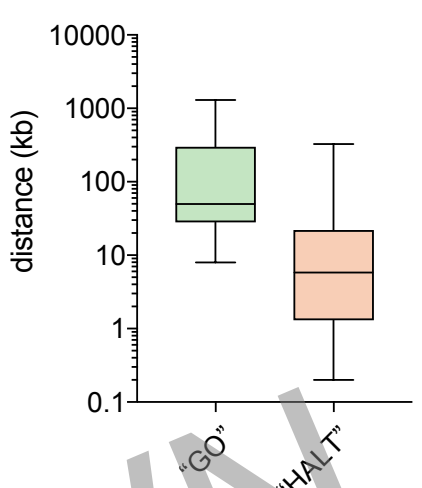

G

$\mathrm{H}$

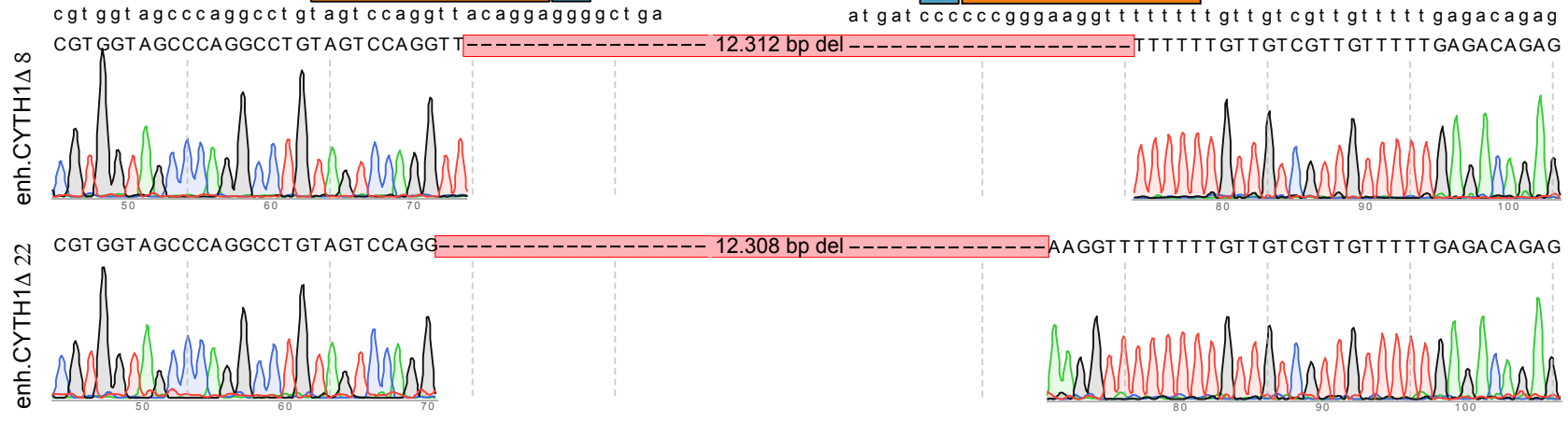

at gat cccccoggaaggt t t t t t gt tgt cgt tgt t t t gagacagag 
Suppl. Fig. 5 - HDAC inhibitors cause openingup of chromatin and enable DNA end resection

bioRxiv reprint dol: https://doi.org/10.1101/691857; this version posted July 3, 2019. The copyright holder for this preprint (which was not A certified by peer review) is the author/funder, who has granted bioRxiv a license to display the preprint in perpetuity. It is made available under RPE-1 $I_{50}$ aCC-BY-NC-ND 4.0 International licensథRE-1 $I_{50}$
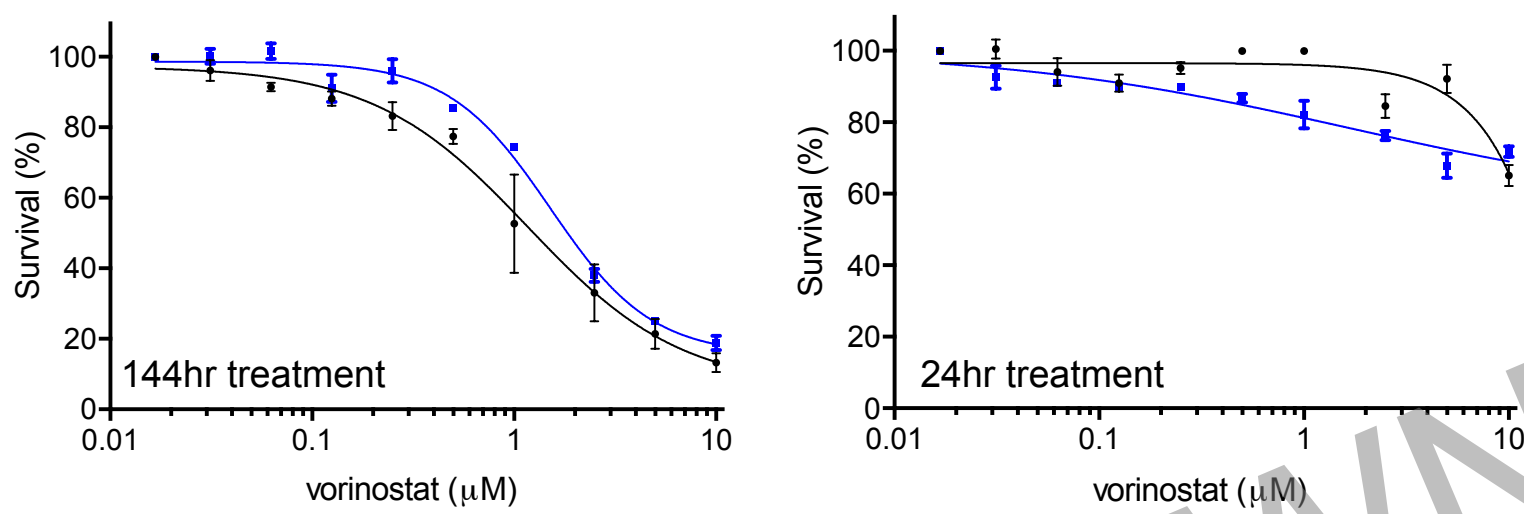

- WT

B

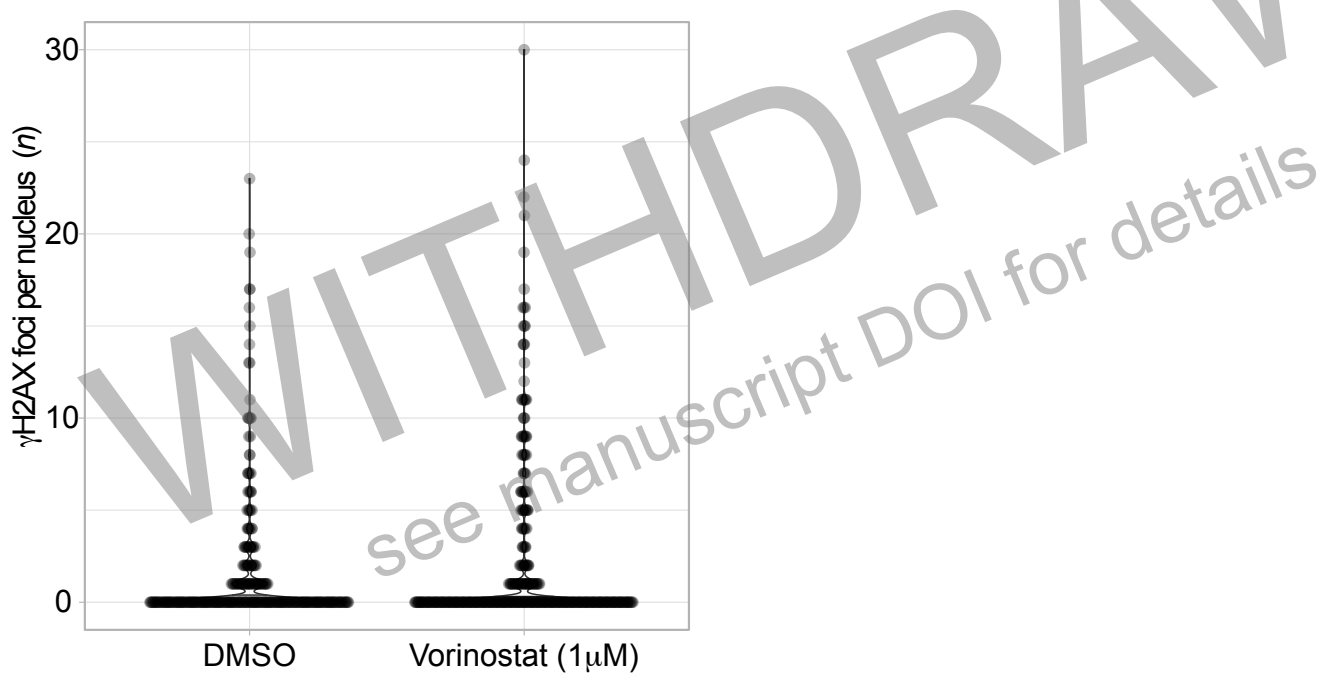

